\title{
A Virtual-Internetworking-Stack (VIS) Approach to Achieve a Flexible, Proprietary Security Model by Augmentation of the Transport Layer under the Collaborative Framework of Sine Wave Encryption Technique and Generation of Color QR Codes
}

\author{
Soham Sengupta ${ }^{1}$ and Parthapratim Sarkar ${ }^{2}$ \\ ${ }^{1}$ Department of Information Technology, JIS College of Engineering, India \\ Research Scholar, DETS, University of Kalyani, India \\ soham.sengupta.java@gmail.com \\ ${ }^{2}$ DETS, University of Kalyani, India \\ parthabe91@yahoo.co.in
}

\begin{abstract}
Due to potentially peer works going on to address the loopholes in the existing system research works in Internet Security is never likely to saturate. The degree of one's need of security on Internet varies with one's economical, organizational and political position and the sensitivity of the information itself. This thesis envisages a Virtual Internetworking Stack (VIS), achieved by augmentation of the TCP/IP stack to befool possible cyber vigilance on one's activities over the Internet. The model prescribes a secure session set-up randomly by exchanging colored QR codes, where the wavelength of the color determines the phase of a sinusoid used to encrypt/decrypt a message, which is understood only by a compatible and intended VIS-stack. Since, the augmentation of TCP/IP layer is done in the Kernel of the user's Operating System, any message that this VIS-stack sends to another VIS-stack across the Internet, will be meaningless to the routers and gateways in between which participate in cyber vigilance; and an attempt to steal one's information will be fooled by the proposed security model. We also present a vulnerability study and performance evaluation of the augmented TCP/IP stack, obtained by results of physically performed experiments.
\end{abstract}

Keywords: Augmentation of TCP/IP stack, Color QR codes, Sine Eave Encryption, Proprietary Security model

\section{Introduction}

Internet is a vast ocean of communication and majority of the world population prefer to communicate over Internet. Like everything else in a communication system, there is need to secure information travelling across different nodes (Routers) of this ocean. The degree of need to secure one's communication depends on one's economical, organizational and political position. For example, a banking portal will demand much more security than a social friendship portal. An e-commerce portal must have better security than a portal that hosts technical discussion forums. Also, we must admit that the email account of a business tycoon or the President of a country will demand more security than a commonplace civilian's. And while it comes to secure a piece of information that relates to the defense of a country, the extreme security is expected, together with the biggest threat of getting it leaked. In certain cases, the trust on one's ISP, too, varies. The defense personnel of a nation must not be as much casual to exchange information with colleagues, as common civilian can be; they 
must not, for example, use public or unauthorized Internet connections for communication. Beyond a certain constraint, one defense personnel may not trust even his fellow comrade, being apprehensive of sabotage. Sometimes, rivalries among big organizations do not allow an employee to communicate certain trade secrets, a patent document for example, using an unauthorized Internet connection. This thesis proposes a security model to incorporate any standard or proprietary Cryptography technique to secure a communication by dint of augmenting the Transport layer of the TCP/IP stack of the user's Operating System. This security model is based on establishing a secure connection by exchanging encrypted bytes of colored QR codes, which carry different parameters to compute the encryption/ decryption key(s). This technique is unique in that, a sine wave is used to encrypt data such that the phase of the wave depends on the timestamp of the message, and that the color of QR codes represents its wave length. The augmentation of transport layer takes care that the key depends on a function of the transport layer (TCP) header. Comprising of all these constraints, the security model envisioned here, allows highly secure communications to take place over a public or unauthorized Internet connection with high assurance of privacy. This is because of the transport layer augmentation which is understood only by the Operating Systems of the communicating machines. The rest of the world is rendered unaware of the data. At the same time, keeping the Network layer intact ensures that the routers, through which the network layer packets must pass across the World Wide Web, will not treat the packets corrupt and hence drop them. So, achieving invincible security system while one uses a public and unauthorized network is the outcome of the thesis. The author carried out successive experiments to test vulnerability and performance (scalability) of the Security model, and presents in this research paper, the results and analysis together with the description of the entire process of augmenting the Transport layer.

\section{Proposed Model}

The security model envisaged in this thesis is achieved by augmentation of the transport layer and introducing just above it an abstract security layer. Throughout the thesis the augmented TCP/IP stack will be referred to as the Virtual Internetworking Stack (VIS) and the introduced security layer as the Opaque Security Layer (OSL). The VIS is shown in Figure 1. The security layer is abstract and opaque because implementation of this very layer is not suggested by the thesis and it does not recommend it to adhere to any standardization. Rather, implementation of this intermediary layer is supposed to use proprietary security algorithms to keep the security architecture as little exposed to the outsider bodies. For example, an application developer, who may be consulted by an organization to develop an secure Network application requiring the augmented stack (VIS), must not require any information about the underlying security mechanisms and nor even the VIS itself. As will appear to a third party software vendor, it is simply a Network application operating in the Application Layer. This will make this security model more flexible to use without compromising the VIS architecture or its implementation to a third party software vendor. The functionality of the VIS involves two major things: 


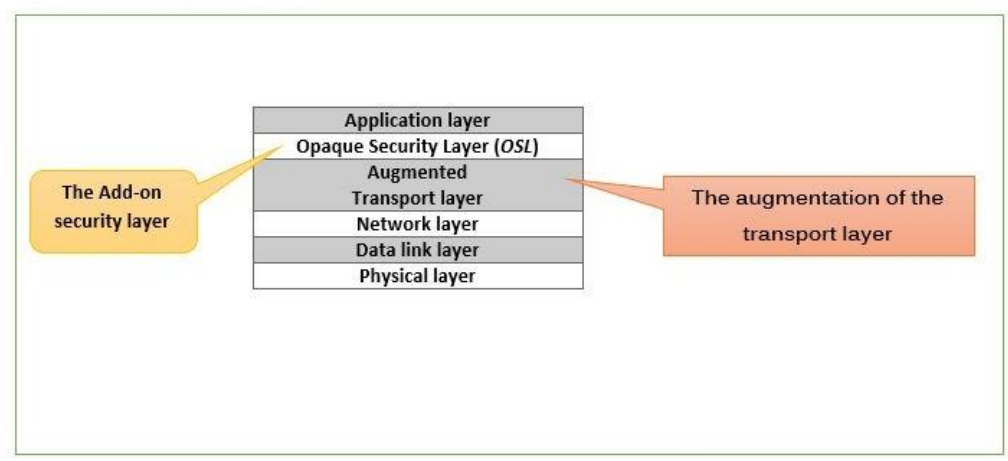

Figure 1. The Schematic Diagram Vis

- A shared knowledgebase that is had with the VIS

- A 4-way secure session set up process between two communication partners. The partner which requests for a secure session is referred to as a Client and who it requests is referred to as a Server. The OSL defines 5 different packet formats as shown in Figure 7. The first four types of packets are used during the process of setting up a secure session, while the last type of packets is a data packet, which is exchanged after a secure session has already been established between the Server and the Client. Section 2.2 presents a detailed discussion on the anatomy of these 5 OSL packets.

\subsection{Shared Knowledgebase}

The shared knowledgebase within the VIS is logically divided to belong to two layers: The OSL layer the augmented Transport Layer. Table 1 shows and explain the implications of the shared knowledgebase in a VIS distributed between the augmented transport layer and the OSL.

Table 1. Shared Knowledgebase of the Augmented Transport Layer

\begin{tabular}{|c|c|c|}
\hline Serial & Entity Name & Description \\
\hline 1 & $\boldsymbol{g}$ (byte[] a) & $\begin{array}{l}\text { A function that operates on TCP header bytes. The } \\
\text { parameter a represents the byte array }\end{array}$ \\
\hline 2 & $f\left(\right.$ long $\left.t_{s}\right)$ & $\begin{array}{l}\text { A function of timestamp of the packet. The parameter } \\
\text { represents the timestamp ( } 8 \text { bytes ) }\end{array}$ \\
\hline 3 & $p$ (double q) & $\begin{array}{l}\text { A function operating on the wavelength of a color light. } \\
\text { The parameter represents the wave length }\end{array}$ \\
\hline 4 & $E(X, K)$ & $\begin{array}{l}\text { A symmetric cryptography algorithm encrypting (or } \\
\text { decrypting) } \mathrm{X} \text { with the } k e y=\mathrm{K}\end{array}$ \\
\hline 5 & $\begin{array}{l}\text { Color-Wavelength } \\
\text { map }\end{array}$ & $\begin{array}{l}\text { This is a hash map of a color and the wave length of light } \\
\text { wave of that color. This is shown in Sec. [1.a] }\end{array}$ \\
\hline
\end{tabular}


Table 1a. COLOR HASH MAP

\begin{tabular}{|l|l|l|r|}
\hline Color & \multicolumn{1}{c|}{ Frequency } & \multicolumn{1}{c|}{ Wavelength } & Average Wavelength \\
\hline Violet & $668-789 \mathrm{THz}$ & $380-450 \mathrm{~nm}$ & $400 \mathrm{~nm}$ \\
\hline Blue & $606-668 \mathrm{THz}$ & $450-495 \mathrm{~nm}$ & $470 \mathrm{~nm}$ \\
\hline Green & $526-606 \mathrm{THz}$ & $495-570 \mathrm{~nm}$ & $550 \mathrm{~nm}$ \\
\hline Yellow & $508-526 \mathrm{THz}$ & $570-590 \mathrm{~nm}$ & $580 \mathrm{~nm}$ \\
\hline Orange & $484-508 \mathrm{THz}$ & $590-620 \mathrm{~nm}$ & $600 \mathrm{~nm}$ \\
\hline Red & $400-484 \mathrm{THz}$ & $620-750 \mathrm{~nm}$ & $700 \mathrm{~nm}$ \\
\hline
\end{tabular}

\subsection{Anatomy of the OSL Packets}

The five OSL packets have the first two fields in common, the Packet Type ( 1 byte) and the Timestamp ( 8 bytes). Since there are 5 packet definitions to the $O S L$, they are assigned five initial identification numbers: $0,1,2,3,4$. However, to strictly identify an incoming packet as belonging to any of these 5 packets, bits of the first field, i.e., the field Packet Type ( 1 byte) is subdivided; the first 3 bits represent the raw-numbers (i.e., 0,1,2,3,4) assigned to an $O S L$ packet. The first 3 bits accommodate the binary equivalents of the numbers $\{0,1,2,3,4\}$, i.e., $(000)_{2},(001)_{2},(010)_{2},(011)_{2},(100)_{2}$ respectively, in binary number system.

The remaining $(8-3)=5$ bits are made to contain the value obtained by performing modulo operation on the timestamp by 32. Because, $\left(2^{5}-1\right)=31$ is the maximum of the unsigned integers we can form with these remaining 5 bits. So, remainder of a positive number (like the timestamp, which is 8 bytes long) by 32 ensures that remainder will never exceed 31.

Value of the field Packet Type of a packet, formed at a timestamp $=\mathbf{T}_{\mathbf{S}}$ is, therefore, $\{x y z$ $b_{4} b_{3} b_{2} b_{1} b_{0}$ expressed in binary, where $\boldsymbol{b}_{4} \boldsymbol{b}_{3} \boldsymbol{b}_{2} \boldsymbol{b}_{1} \boldsymbol{b}_{0}$ is the binary representation of ( $\boldsymbol{T}_{S} \boldsymbol{m o d}$ 32 ); whereas ( $\mathrm{x} \mathrm{y} \mathrm{z})_{2}$ represent the raw number assigned to the packet type. So, for the first packet type these three bits are 000 to represent the type $=0$. The calculation of the value of the first byte of an OSL Packet is discussed in Algorithm 1 Table 2 which also takes a look at the anatomy of all these five packets.

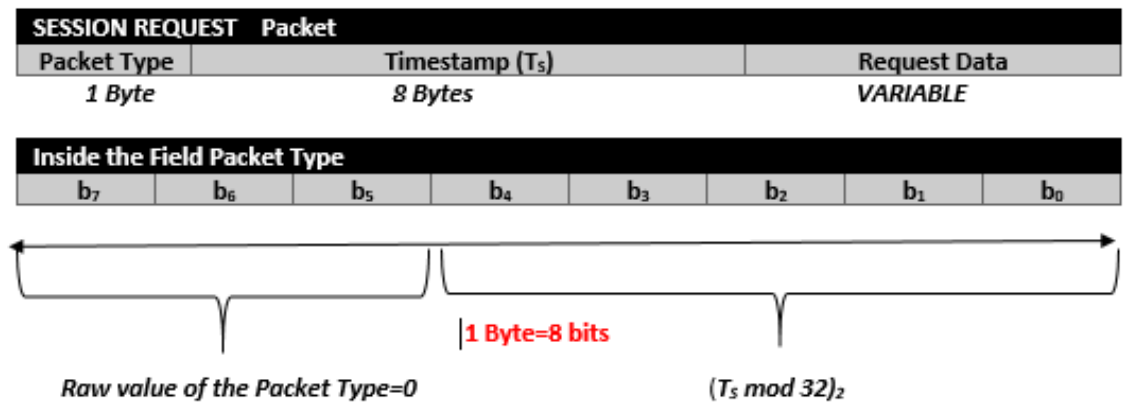

$(000)$

Among the 5 OSL packets, the first one is referred to as the SESSION REQUEST packet. It has 3 fields: Packet Type (1 byte), Timestamp ( 8 bytes) and Request-DATA field (variable). The first 3 bits of this packet are $\{000\}$. 
Value of the field Packet Type of a SESSION REQUEST Packet formed at a timestamp, 13835440 80111 , is therefore $=(15)_{10}$. This can be calculated as below:

\section{Table 2. Anatomy of the OSL Packets}

\section{Algorithm 1: Generic Calculation of the value of the field Packet-Type for all 5 OSL Packets}

1 The raw value of the packet type is expressed in 3-bit binary and are accommodated in 3 Most Significant Bits of the field Packet-Type.

Examples:

a. The raw value assigned to a SESSION REQUEST packet is $\mathbf{0}$. So the most significant 3 bits in this field contain $\{000\}$.

b. The raw value assigned to a CHALLENGE PACKET is 1 . So the 3 most significant bits in this field of this very type of OSL packets contain $\{001\}$.

c. The raw value assigned to a RESPONSE PACKET is 2 . So the 3 most significant bits in this field of this type of OSL packets contain $\{010\}$.

d. The raw value assigned to an $F$ is 3 . So the 3 most significant bits in this field of this type of $O S L$ packets contain $\{011\}$.

e. The raw value assigned to a DATA COMMUNICATION PACKET is 4 . So the 3 most significant bits in this field of this very type of OSL packets contain $\{100\}$.

2 Let $\boldsymbol{T}_{s}$ be the timestamp when an OSL packet was formed.

We obtain the remainder $\boldsymbol{R}$ by division of $\boldsymbol{T}_{s}$ with the divisor 32 . Thus, $\boldsymbol{R}=\boldsymbol{T}_{s} \bmod 32$

This is expressed in binary and since $\boldsymbol{R}<32$, it can be accommodated in the remaining 5 bits of the 8-bit field.

3 Now the final value of the 8-bit field is calculated. Examples: (Assuming the $T_{S}=13835440$ 80,111)

$R=15$ i.e. $(01111)_{2}$

a. For the SESSION REQUEST packet this value is $\{00001111\}_{2}=15$

b. For the CHALLENGE PACKET this value is $\{00101111\}_{2}=47$

c. For the RESPONSE PACKET this value is $\{010 \mathbf{0 1 1 1 1}\}_{2}=\mathbf{7 9}$

d. For the OSL-ACKNOWLEDGMENT PACKET this value is $\{\underline{011} \mathbf{0 1 1 1 1}\}_{2}=111$

e. For the Data Communication packet this value is $\{10001111\}_{2}=143=-113$ (overflown to fit in 8 bit signed integer arithmetic)

Note: The 3 most significant bits which accommodate the raw numbers, are underlined 


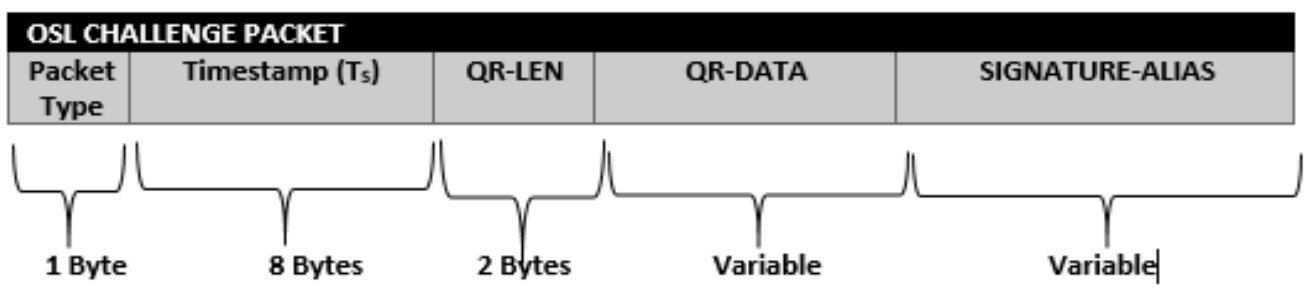

In a CHALLENGE PACKET the Size of the field $Q R-D A T A=$ the Value of the field $Q R-L E N$
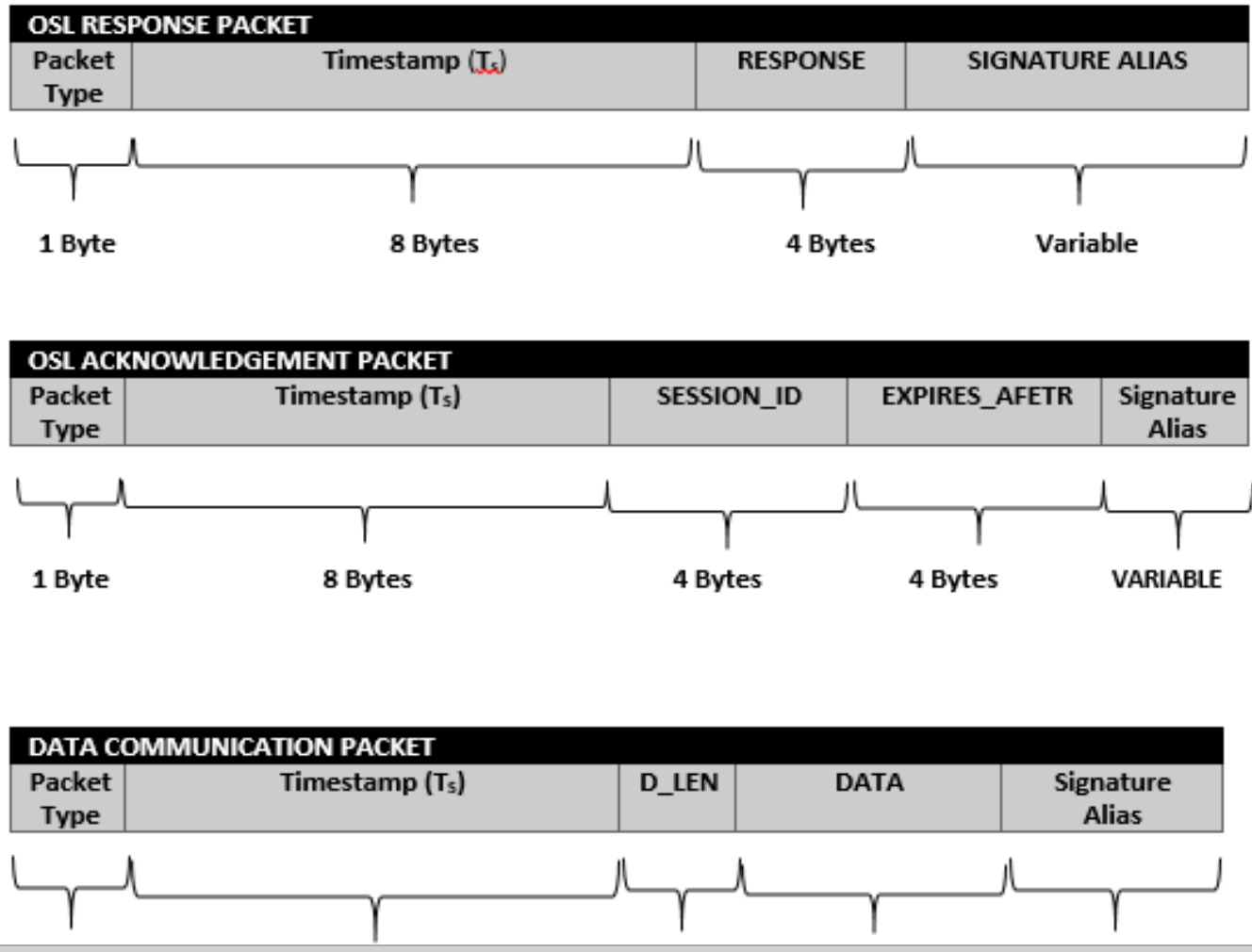

In DATA COMMUNICATION PACKET, the size of the DATA field= the value of the field D_LEN

Initially the Client sends this packet asking the Server to set up and open a secure opaque session. The Server sends a challenge packet, the second of the 5 OSL packets, to the Client. This packet, referred to as the CHALLENGE PACKET, consists of five fields, Packet Type (1 byte), Timestamp ( 8 bytes) QR-LEN (2 bytes), QR-DATA (variable) and SIGNATUREALIAS (variable). The value of Packet Type field is calculated is above, treating the packet type to be $(1)_{10}$ i.e., $(001)_{2}$.

The third packet is a RESPONSE packet, containing four fields, Packet Type (1 byte), Timestamp ( 8 bytes), RESPONSE ( 4 bytes) and SIGNATURE-ALIAS (variable). The first two fields, packet type and timestamp have same implication as in the previous two packets; and the first 3 bits of first field, i.e., Packet Type, accommodate the value $(2)_{10}=(010)_{2}$.

The fourth of these OSL packets is an acknowledgement that the Server sends to the Client acknowledging that a secure opaque session has been set up and how long it will be valid. The fields of this acknowledgement packet are Packet Type (1 byte), Timestamp ( 8 bytes), 
Session ID_(4 bytes), SESSION EXPIRES AFETR (4 bytes), and a SIGNATURE ALIAS (variable). The first three bits of the field Packet Type accommodate the decimal number $\mathbf{3}$, i.e., (101) ${ }_{2}$. This is referred to as the OSL Acknowledgement Packet.

The last of the OSL packet types is a Data Communication packet, which the communicating partners i.e., the Client and the Server exchange between themselves after an opaque, secure session has been established. This packet consists of the following five fields: Packet Type (1 byte), Timestamp ( 8 bytes), D_LEN ( 2 bytes), DATA (variable) and the SIGNATURE ALIAS (variable). The first 3 bits of the first field, i.e., Packet Type accommodate the decimal number 4 , represented as $(100)_{2}$.

\subsection{Secure Session Establishment}

As overviewed in Section 2.2, the process of establishing an OSL session between two communicating partners is shown in the timeline-diagram presented in Figure 2. The session is set up following successful completion of 4 phases of packet exchange.

2.3.1. Session Request: The Client requests the Server to set up an $O S L$ session by sending a SESSION REQUEST Packet. This process of generating a request at the Client stack (VIS) is described in Algorithm 2 Table 3. The request is received and understood by the Server to be a request at the transport layer. The layers below, however, cannot have a clue of this. The transport layer is such augmented that in a receiving stack (VIS), it will deliver any of the five $O S L$ packets to the $O S L$ layer, instead of forwarding it directly to the Application layer. The processing logic of a SESSION REQUEST packet is described in Table 4. The table also illustrates how the VIS of the Server creates a CHALLENGE PACKET for the Client.

\section{Table 3. Formation of Session Request Packet}

\begin{tabular}{|c|c|c|}
\hline 0 & 1 & $\begin{array}{l}\text { The OSL of the Client VIS picks the current timestamp }\left(t_{0}\right) \text { of system, and } \\
\text { calculates a value } K \text { with its knowledgebase function } f(t) \text {. } \\
\text { Outcome of this step: } K=f\left(t_{0}\right)\end{array}$ \\
\hline$S$ & 2 & $\begin{array}{l}\text { Each } V I S \text { has authentication parameters (user id and password) which identify } \\
\text { the user of the computer within an Organization. Let us assume that the Client } \\
\text { VIS has } U \text { and } P \text { as the user id and the password. } \\
\text { The } O S L \text { encrypts these two parameters using a common symmetric } \\
\text { cryptography algorithm } E \text { and using } K \text { as the key. } \\
\text { A String } S \text { is obtained from } U^{\prime} \text { and } P^{\prime} \text { using [Algorithm 3.1] described in [Table-10] } \\
\text { Outcome of this step: } \\
U^{\prime}:=E(U, K) \text { and } P^{\prime}:=E(P, K) \\
S:=\Sigma\left(U^{\prime}, P^{\prime}\right) \text {, here the operator } \Sigma \text { represents string generation operation } \\
\text { Algorithm } 3.1 \\
\text { [Table-10] }\end{array}$ \\
\hline L & 3 & $\begin{array}{l}\text { A color is picked up at random from the Color-Frequency Hash Map shown in } \\
\text { Table } 1\end{array}$ \\
\hline
\end{tabular}




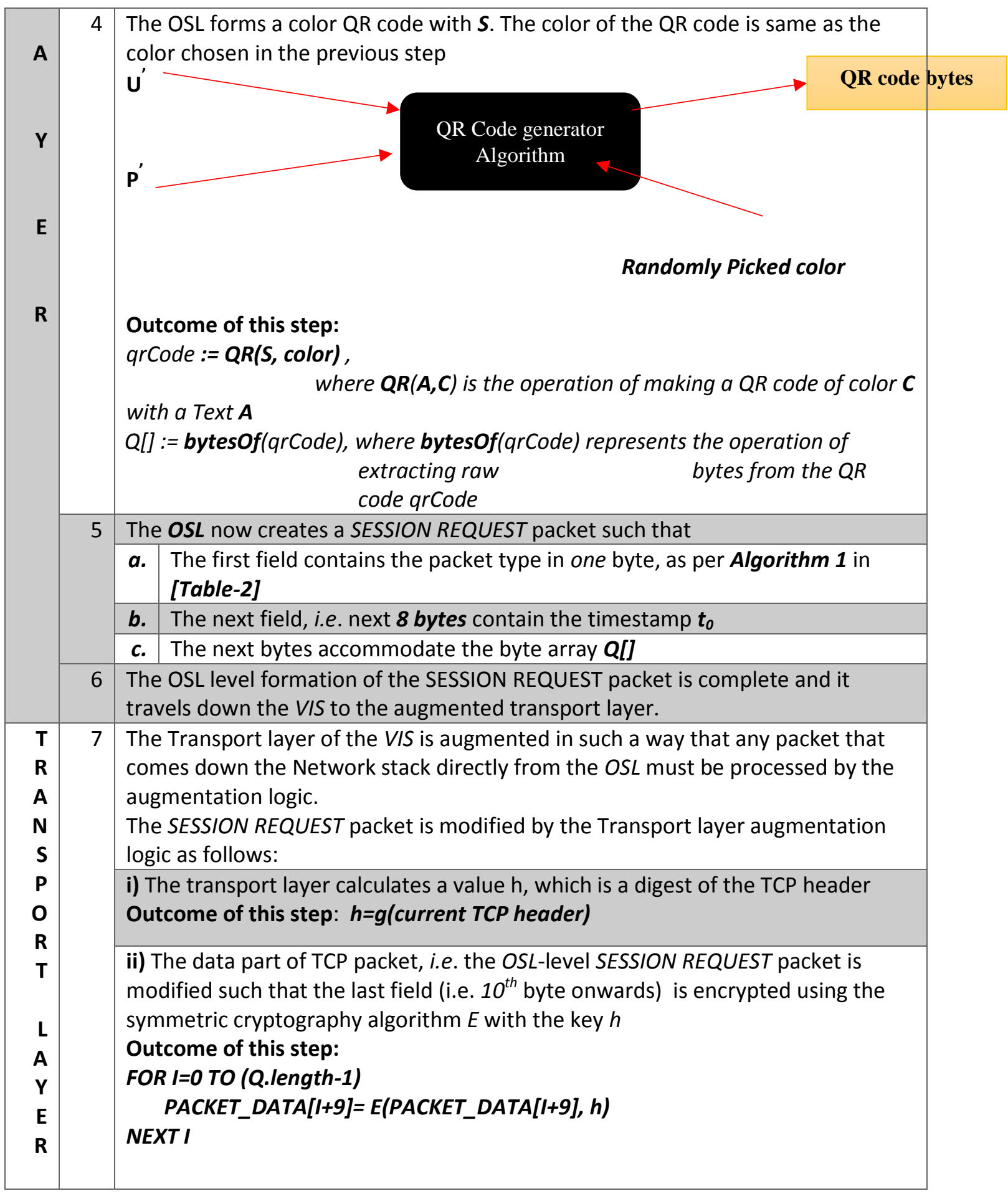




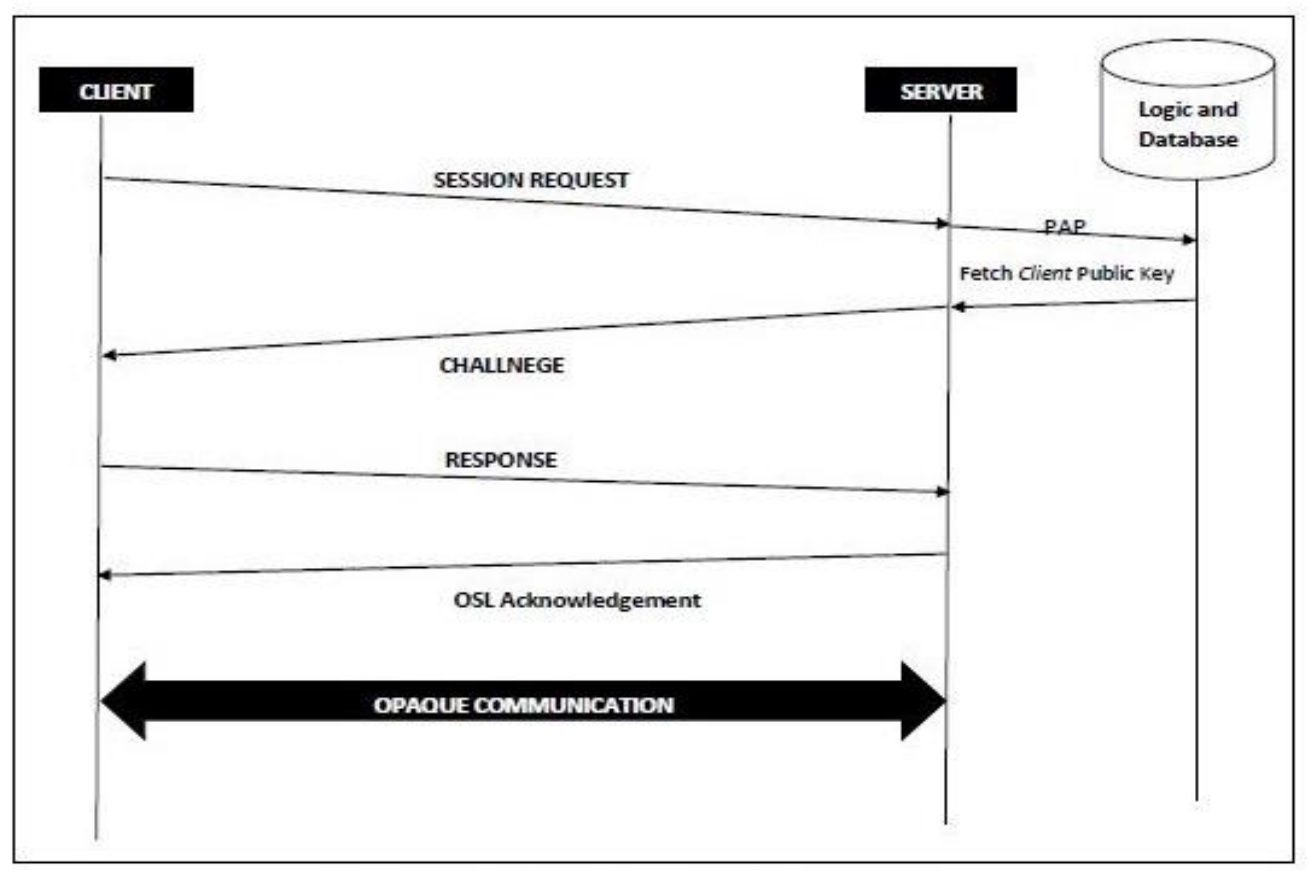

Figure 2. Timeline Diagram of Secure Set-up

The Packets Defined by the OSL Layer
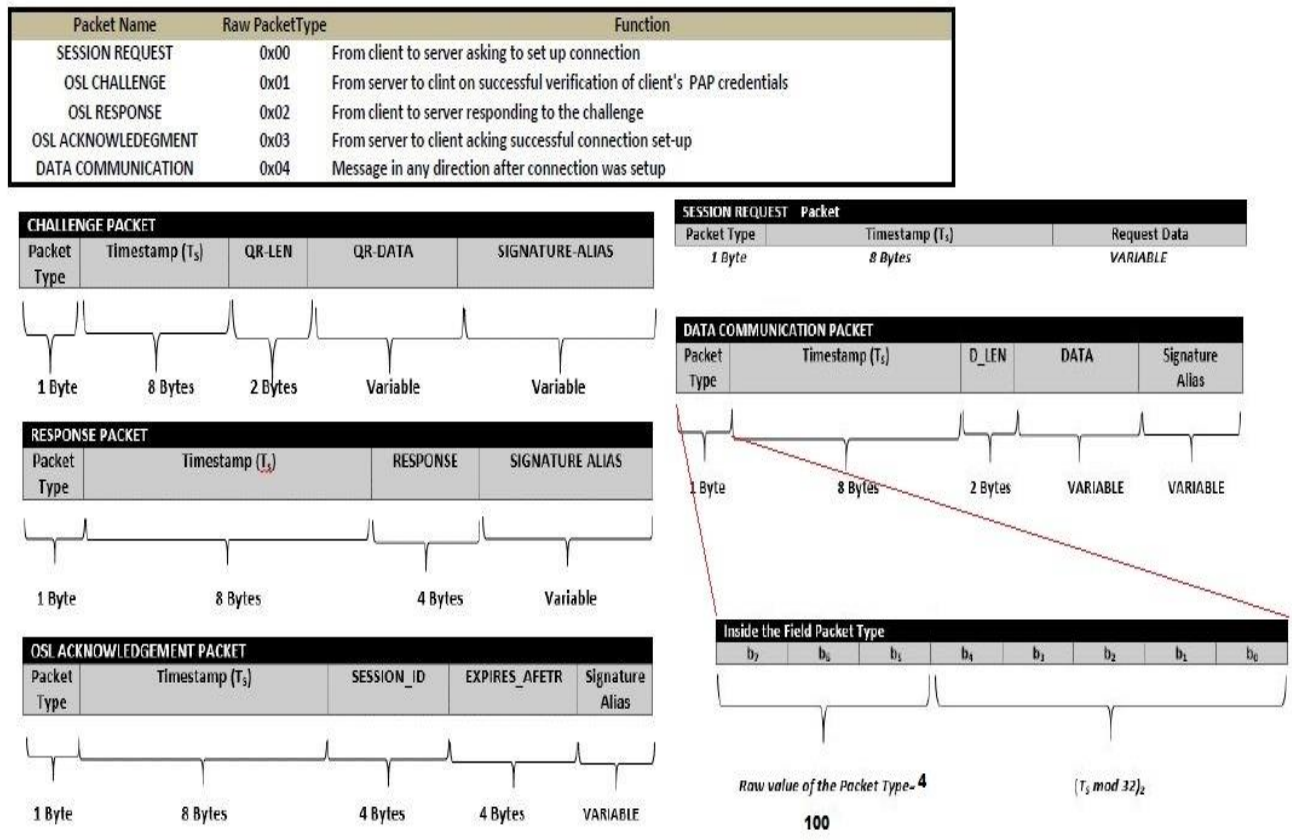

1 Byte $=8$ bits

Figure 7. Packets Defined by the VIS 
Table 4. Algorithm 3

ALGORITHM 3: PROCESSING OF SESSION REQUEST PACKET AND FORMATION OF THE CHALLENGE PACKET AT THE SERVER (RECEIVER) VIS

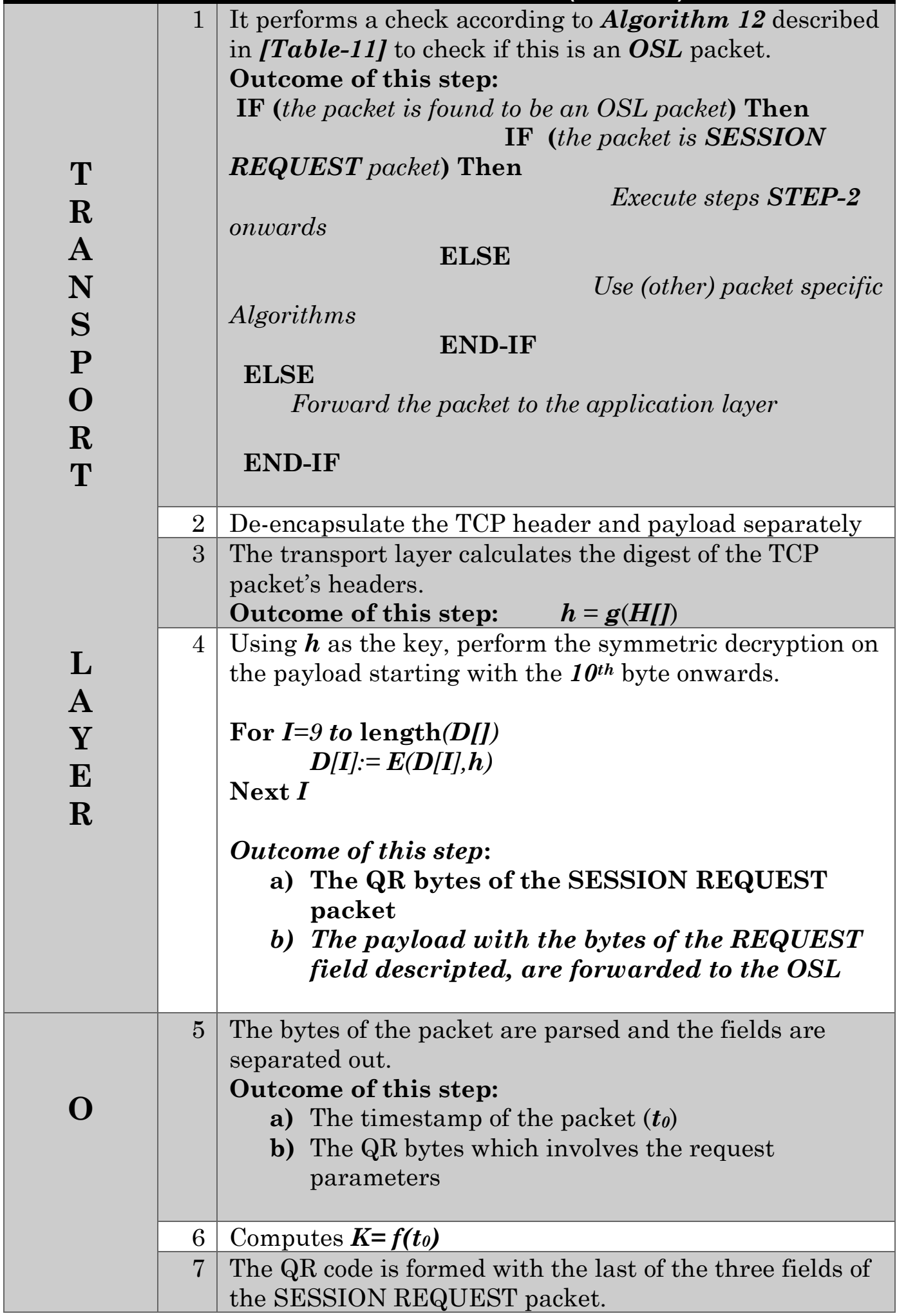




\begin{tabular}{|c|c|c|}
\hline $\mathbf{S}$ & & Outcome of this step: the $Q R$ code \\
\hline \multirow[t]{2}{*}{$\mathbf{L}$} & 8 & $\begin{array}{l}\text { From } \mathrm{QR} \text { code the text }(\boldsymbol{S}) \text { is extracted. Also, the color of } \\
\text { the } \mathrm{QR} \text { code is found out. } \\
\text { Outcome of this step: } \\
\text { a) } \mathrm{S}:=\boldsymbol{Q} \boldsymbol{R}^{-1} \text { (qrCode) } \\
\text { b) color:= colorOf( } \mathrm{qrCode}) \\
\text { c) } \boldsymbol{\lambda}=\text { wavelength(color) }\end{array}$ \\
\hline & 9 & $\begin{array}{l}\text { The QR text obtained in the previous step is parsed to } \\
\text { yield the encrypted user id and password } \\
\text { Outcome of this step: } \\
\text { a) } \boldsymbol{U} \\
\text { b) } \boldsymbol{P}\end{array}$ \\
\hline $\mathbf{L}$ & 10 & $\begin{array}{l}\text { With } \boldsymbol{K} \text { as the key, the symmetric decryption, } \boldsymbol{E} \text { is } \\
\text { carried out to find the user id and password: } \\
\boldsymbol{U}:=\boldsymbol{E}\left(\boldsymbol{U}^{\prime}, \boldsymbol{K}\right) \boldsymbol{P}:=\boldsymbol{E}(\boldsymbol{P}, \boldsymbol{K}) \\
\text { Outcome of this step: } \boldsymbol{U} \text { and } \boldsymbol{P} \text { (User authentication } \\
\text { parameters) }\end{array}$ \\
\hline $\mathbf{A}$ & 11 & $\begin{array}{l}\text { The user id and password are looked up for a match in a } \\
\text { user database. The authentication is carried out using a } \\
\text { local or remote database. } \\
\text { IF authentication fails Then } \\
\text { o Block connection } \\
\text { O Take an action to prevent farther attacks } \\
\text { [This step is Optional and is directly NOT a } \\
\text { part of the envisaged security mode] }\end{array}$ \\
\hline $\mathbf{E}$ & & $\begin{array}{l}\text { ELSE } \\
\quad \text { Perform steps } 12 \text { onwards } \\
\text { END-IF }\end{array}$ \\
\hline \multirow{6}{*}{$\mathbf{R}$} & 12 & $\begin{array}{l}\text { Fetch the Public Key of the user (authenticated in step- } \\
\text { 11) from a database maintained under PKI }\end{array}$ \\
\hline & 13 & $\begin{array}{l}\text { Generate two random numbers. } \\
\text { Outcome of this step: } \\
\text { a) A:= } \operatorname{Rnd}() \\
\text { b) } X:=\boldsymbol{R} n d()\end{array}$ \\
\hline & 14 & $\begin{array}{l}\text { Compute the p-Function of the wavelength of the color } \\
\text { found out in } \boldsymbol{S T E P}-\boldsymbol{8 c} \\
\text { Outcome of this step: } \quad \boldsymbol{W}=\boldsymbol{p}(\boldsymbol{\lambda})\end{array}$ \\
\hline & 15 & $\begin{array}{l}\text { The two numbers are symmetrically encrypted using the } \\
\text { key, } W \\
\text { Outcome of this step: } \\
\qquad \begin{array}{l}\text { a) } A^{\prime}:=\boldsymbol{E}(\mathrm{A}, \mathrm{W}) \\
\text { b) } \mathrm{X}^{\prime}:=\boldsymbol{E}(\mathrm{X}, \mathrm{W})\end{array}\end{array}$ \\
\hline & 16 & $\begin{array}{l}\text { Create a random integer to be used as the Challenge. } \\
\text { Outcome of this step: } \quad \mathbf{C}:=\mathbf{R n d}()\end{array}$ \\
\hline & 17 & $\begin{array}{l}\text { Fetch self-timestamp (timestamp of itself). } \\
\text { Outcome of this step: } \mathbf{t}_{1}:=\text { Self-timestamp }\end{array}$ \\
\hline
\end{tabular}




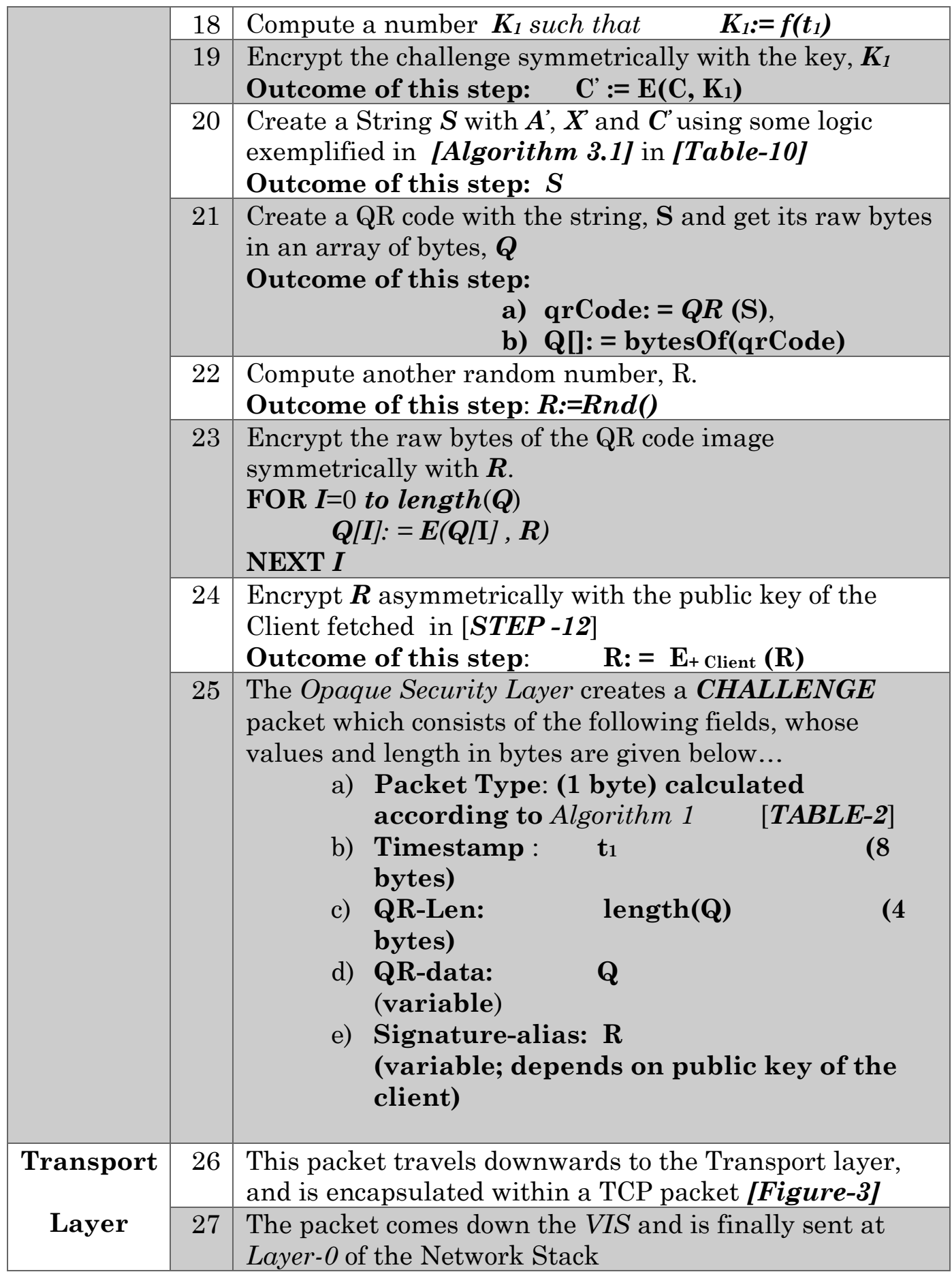

2.3.2 Processing of the Challenge Packet at the Client VIS: When the Client receives the challenge from the server, the Transport layer of the VIS recognizes it to be a challenge packet. The Transport layer de-encapsulates and processes it before forwarding it to the upper layer, i.e., the $\boldsymbol{O S L}$. The $\boldsymbol{O S L}$ layer processes the augmented transport layer packet and creates a response to challenge. The processing the CHALLENGE PAKCET is described in Algorithm 4 Table 5. 


\section{Table 5. Algorithm 4}

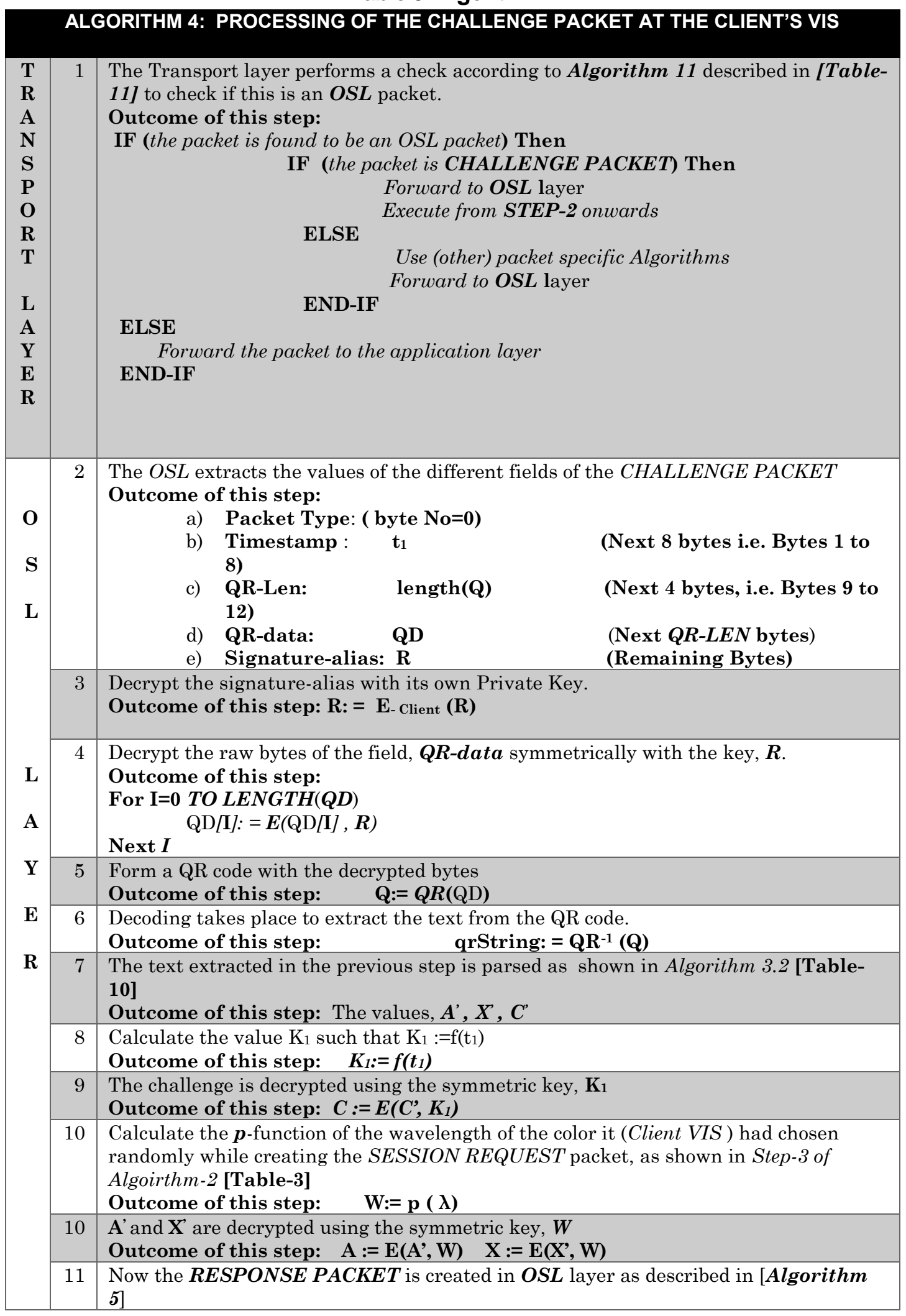




\section{Table 5.1. Algorithm 5}

\begin{tabular}{|c|c|c|c|c|}
\hline & & \multicolumn{3}{|c|}{ ALGORITHM 5: CREATION OF THE RESPONSE PACKET } \\
\hline \multirow{13}{*}{ OSL Layer } & 1 & \multicolumn{3}{|c|}{$\begin{array}{l}\text { Calculate the current timestamp of the system } \\
\text { Outcome of this step: } \quad t_{\mathbf{2}}=\text { current timestamp in milliseconds }\end{array}$} \\
\hline & 2 & \multicolumn{3}{|c|}{ Calculate the value $\left(k_{2}\right)$ of the timestamp function such that $\boldsymbol{k}_{2}:=f\left(t_{2}\right)$} \\
\hline & 3 & $\begin{array}{l}\text { The values } A, X \text { obta } \\
\text { equation of a sine } w^{-} \\
A \sin \frac{2 \pi}{\lambda}(c * t-x) \\
\text { where } t=k_{2} \text { and } x= \\
\text { Outcome of this ster } \\
\text { where } c=3=3 \times 10^{8} \% \\
\text { [the velocity of light }\end{array}$ & $\begin{array}{l}\text { in Step-10 of Algorithn } \\
\text { xpressed as, } \\
:=A \sin \frac{2 \pi}{\lambda}(c * f(t 2) \\
\text { Icuum space expressed }\end{array}$ & $\begin{array}{l}4 \text { are used in the } \\
y(t, x)= \\
-X), \\
\left.m-\sec ^{-1} / 10^{8}\right]\end{array}$ \\
\hline & 4 & \multicolumn{3}{|c|}{$\begin{array}{l}\text { A random number, } R_{2} \text { is generated } \\
\text { Outcome of this step: } \mathbf{R}_{\mathbf{2}}:=\mathbf{r n d}()\end{array}$} \\
\hline & & \multicolumn{3}{|c|}{$\begin{array}{l}\text { A one-time key } K_{2} \text {, is computed to be the } X O R \text { of } y_{2} \text { and } R_{2} \\
\text { Outcome of this step: } K_{\mathbf{2}}:=\mathbf{y}_{\mathbf{2}} \boldsymbol{\Phi} \mathbf{R}_{\mathbf{2}}\end{array}$} \\
\hline & 6 & \multicolumn{3}{|c|}{$\begin{array}{l}\text { The challenge, i.e. } \boldsymbol{C} \text { is encrypted symmetrically with the one-time key, } \\
\boldsymbol{K}_{2} \text {, to form the response } \\
\text { Outcome of this step: } \quad C_{\text {cipher }}:=E\left(C, K_{2}\right)\end{array}$} \\
\hline & 7 & \multicolumn{3}{|c|}{$\begin{array}{l}R_{2} \text { is encrypted asymmetrically with the private key of the Client. } \\
\text { Outcome of this step: } \mathbf{R}_{\mathbf{2}}:=E_{\text {-client }}\left(\mathbf{R}_{\mathbf{2}}\right)\end{array}$} \\
\hline & \multirow[t]{6}{*}{8} & \multicolumn{3}{|c|}{$\begin{array}{l}\text { The Response packet is created as below and forwarded to the transport } \\
\text { layer. }\end{array}$} \\
\hline & & Field Name & Field Size in Bytes & Value of the Field \\
\hline & & Packet Type & 1 & $\begin{array}{l}\text { calculated according } \\
\text { to Algorithm } 1 \\
\text { [TABLE-2] }\end{array}$ \\
\hline & & Timestamp & 8 & $\mathrm{t}_{2}$ \\
\hline & & Response & 4 & $C_{\text {Cipher }}$ \\
\hline & & Signature-Alias & Variable & $R_{2}$ \\
\hline $\begin{array}{l}\text { Transport } \\
\text { Layer }\end{array}$ & 1 & \multicolumn{3}{|c|}{ Transport Layer forwards it to the Network Layer down the VIS } \\
\hline
\end{tabular}

After processing the challenge, the client VIS responds to the challenge. The formation of the RESPONSE PACKET is illustrated in Algorithm 5 Table-5.1

2.3.3 Verifying the Response at the Server VIS: After the Server receives the response, it is recognized to be a RESPONSE PACKET at the Transport Layer of the VIS. The response is verified by the $O S L$ layer as per Algorithm 6 Table 6. On successful verification of the response, the Server sends an Acknowledgement packet which contains the session id and session validity. The process of generating an acknowledgment is described in Algorithm 7 Table 7 
Table 6. Algorithm 6

\section{ALGORITHM 6: PROCESSING OF THE RESPONSE PACKET THE SERVER} VIS

1 The Transport Layer performs a check according to Algorithm 11 described in

[Table-11] to check if this is an OSL packet.

Outcome of this step:

IF (the packet is found to be an OSL packet) Then

IF (the packet is RESPONSE PACKET) Then

Forward to $\boldsymbol{O S L}$ layer

Execute STEP-2 onwards

ELSE

Use (other) packet specific Algorithms

END-IF

Forward to OSL layer

ELSE

Forward the packet to the application layer

END-IF

2 The packet is de-encapsulated at the OSL layer. The fields of the payloads are extracted

Outcome of this step:

- The timestamp $\left(t_{2}\right)$ of the packet $\left(2^{\text {nd }}\right.$ Byte to $9^{\text {th }}$ Byte $)=$ 8 bytes

- The response $(\mathrm{R}) \quad\left(10^{\text {th }}\right.$ Byte to $13^{\text {th }}$ Byte) $=4$ Bytes

- The Signature Alias(S)

(14 ${ }^{\text {th }}$ Byte onwards)

3 Compute the value $\left(\mathrm{k}_{2}\right)$ of timestamp function

Outcome of this step: $\quad k_{2}:=f\left(t_{2}\right)$

4 Decrypt the Signature by the public key of the Client

Outcome of this step: : $\mathbf{R}_{\mathbf{2}}:=\mathbf{E}+$ Client $(\mathrm{S})$

L 5 Computes the value of the magnitude (Positive value of the amplitude)

A of the Sine Wave.

Outcome of this step:

$\mathrm{y}_{2}:=\left|A \sin \frac{2 \pi}{\lambda}(c * f(\mathrm{t})-x)\right|$ where $\mathrm{t}=\mathrm{t}_{2}, \& \mathrm{~A}, \lambda$ have already been exchanged in earlier phases

$c=3=3 x 108 / 10^{8}=$ [the velocity of light in vacuum space expressed in $m$-sec $\left.{ }^{-1} / 10^{8}\right]$

6 Computes the one-time key $\left(\boldsymbol{K}_{2}\right)$

$\mathbf{K}_{\mathbf{2}}:=\mathbf{R}_{\mathbf{2}} \boldsymbol{\Phi} \mathbf{y}_{\mathbf{2}}$

7 The response, i.e. $\boldsymbol{C}$ is decrypted symmetrically with $\boldsymbol{K}_{\mathbf{2}}$

Outcome of this step: $\mathrm{C}_{1}:=\mathrm{E}\left(\mathrm{R}, \mathrm{K}_{2}\right)$

$8 \mathrm{C}:=$ The challenge generated by the Server OSL in STEP-16 of Algorithm 3 [Table-4] 
IF $\mathrm{C}_{1}==C$ Then

a) Accept to communicate with the Client

b) Create an OSL ACKNOWLEDGEMENT PACKET and send it to client illustrated in [Algorithm 7]

c) Continue communication till client does or session expires, whichever is earlier

ELSE

a) Decline the connection

b) [Optionally] Take action against Cyber intrusion according to policies END IF of the respective organization.

\section{Table 7. Final Step of 4-way Session Establishment Generation of} Acknowledgement

\section{ALGORITHM 7: CREATION OF OSL ACKNOWLEDGEMENT PACKET AT THE SERVER VIS}

1 Generates a unique session ID $\left(S_{-} I D\right)$ which the server maintains in a database.

[Table-7] shows a sample table schema of a session table.

$2 \quad \boldsymbol{t}_{\mathbf{3}}:=$ Current Timestamp

0

$\mathbf{S}$

$\mathbf{L}$

3 Compute the validity of the session in milliseconds

Outcome of this step: VT:= validity of the session elapsed since t3 (In milliseconds)

4 Generate a random number. Outcome of this step: $\quad R:=r n d()$

5 Computes the magnitude of the sine wave using current timestamp Outcome of this step: $\quad \mathrm{y}_{3}:=\left|A \sin \frac{2 \pi}{\lambda}(c * f(\mathrm{t})-x)\right|$ where $\mathrm{t}=t_{3}$

6 Compute the $p$-value of the wavelength Outcome of this step: $w:=p(\lambda)$

7 Compute the symmetric key for encrypting the session id composited by $\boldsymbol{y}_{3}$ and $\boldsymbol{R}$

Outcome of this step: $\mathrm{Z}_{1}:=\mathrm{y}_{3} \Phi \mathrm{R}$

8 Compute the symmetric key for encrypting the value of Valid-Till field composited by $\boldsymbol{w}$ and $\boldsymbol{R}$

Outcome of this step: $\mathrm{Z}_{2}:=\mathrm{w} \Phi \mathrm{R}$

9 Encrypt the session id symmetrically with the key, $\mathbf{Z}_{1}$ Outcome of this step: $S_{-} I D:=E\left(S \_I D, Z_{1}\right)$

10 Encrypt the $\boldsymbol{V} \boldsymbol{T}$ field by $\boldsymbol{Z}_{2}$

Outcome of this step: $V T:=E\left(V T, Z_{2}\right)$

11 Encrypt R with the public key of the Client to form a SIGNATURE ALIAS Outcome of this step: $\quad \mathrm{S}:=\mathrm{E}+$ Client (R)

12 Create the OSL Acknowledgement Packet with the following fields and forwards it to the Transport Layer.

\begin{tabular}{|c|c|c|c|}
\hline Field Name & Field Position & $\begin{array}{c}\text { Field Size in } \\
\text { Bytes }\end{array}$ & Field Value \\
\hline Packet Type & $1^{\text {st }}$ Byte & 1 Byte & $\begin{array}{l}\text { Calculated } \\
\text { according to } \\
\text { Algorithm } 1 \\
\text { [TABLE-2] }\end{array}$ \\
\hline Timestamp & $\begin{array}{c}2^{\text {nd }} \text { Byte }-9^{\text {th }} \\
\text { Byte }\end{array}$ & 8 Bytes & $t_{3}$ \\
\hline Session Validity & $\begin{array}{c}10^{\text {th }} \text { Byte }-13^{\text {th }} \\
\text { Byte }\end{array}$ & 4 Bytes & $V T$ \\
\hline Session ID & $\begin{array}{l}14^{\text {th }} \text { Byte }-17^{\text {th }} \\
\text { Byte }\end{array}$ & 4 Bytes & S_ID \\
\hline $\begin{array}{c}\text { Signature } \\
\text { ALIAS }\end{array}$ & $\begin{array}{c}18^{\text {th }} \text { bytes } \\
\text { onwards }\end{array}$ & VARIABLE & $S$ \\
\hline
\end{tabular}




\subsection{Data Communication Post Establishment of a Secure Session}

After a secure session has been established between the Server and the Client, communication can continue until the session expires or they mutually end the session, whichever takes place earlier. The process of encryption of a DATA PACKET at the senderside VIS is illustrated in Algorithm 8 Table 8. Algorithm 9 Table 9 depicts how a receiver-side VIS processes and decrypts a DATA PACKET. Both the tables present respective algorithms with layer-wise break-up to help us understand how the augmentation of the Transport layer and the Opaque Security Layer (OSL) collaborate with each other in a VIS.

\section{Table 8. Algorithm 8}

\begin{tabular}{|c|c|c|}
\hline $\begin{array}{l}\text { Application } \\
\text { Layer }\end{array}$ & 1 & $\begin{array}{l}\text { Generate application data bytes } \boldsymbol{D}[] \text {. The data is forwarded to } \\
\text { the } \boldsymbol{O S L} \text { layer. }\end{array}$ \\
\hline & 2 & $\begin{array}{l}\text { Fetch the system timestamp }\left(\boldsymbol{t}_{s}\right) \\
\text { Outcome of this step: } \boldsymbol{t}_{\boldsymbol{s}}:=\text { current timestamp }\end{array}$ \\
\hline & 3 & $\begin{array}{l}\text { The } p \text {-function of the wavelength is calculated } \\
\text { Outcome of this step: } \mathbf{W}:=p(\boldsymbol{\lambda})\end{array}$ \\
\hline & 4 & $\begin{array}{l}\text { The value }\left(\mathrm{K}_{S}\right) \text { of time-function is computed. } \\
\text { Outcome of this step: } K_{S}:=f\left(t_{S}\right)\end{array}$ \\
\hline & 5 & $\begin{array}{l}\text { Generate a random number, } R \\
\text { Outcome of this step } \quad R:=\operatorname{Rnd}()\end{array}$ \\
\hline & 6 & 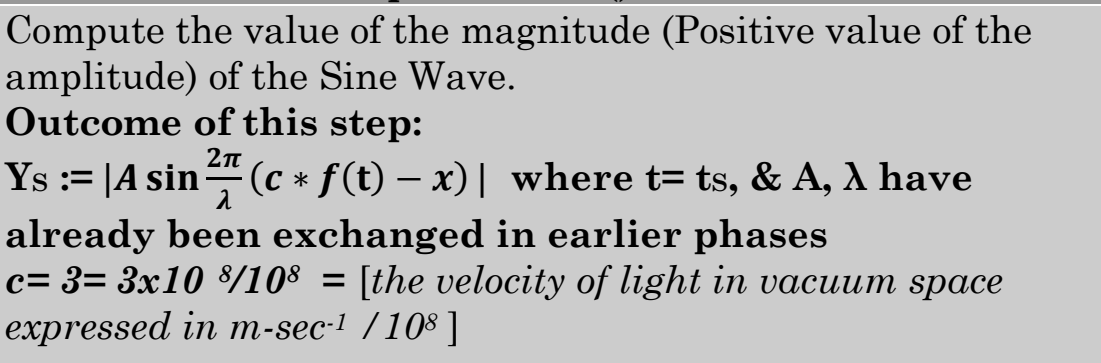 \\
\hline & 7 & $\begin{array}{l}\text { Two one-time key-aliases }\left(Z_{1} \text { and } Z_{2}\right) \text { are calculated with } R \text {, } \\
Y_{S} \text { and } W \text {. } \\
\text { Outcome of this step: } \quad Z_{1}:=\mathbf{R} \Phi \mathbf{Y S}_{S} \text { and } \mathbf{Z}_{2}:= \\
\mathbf{R} \Phi \mathbf{W}\end{array}$ \\
\hline & 8 & 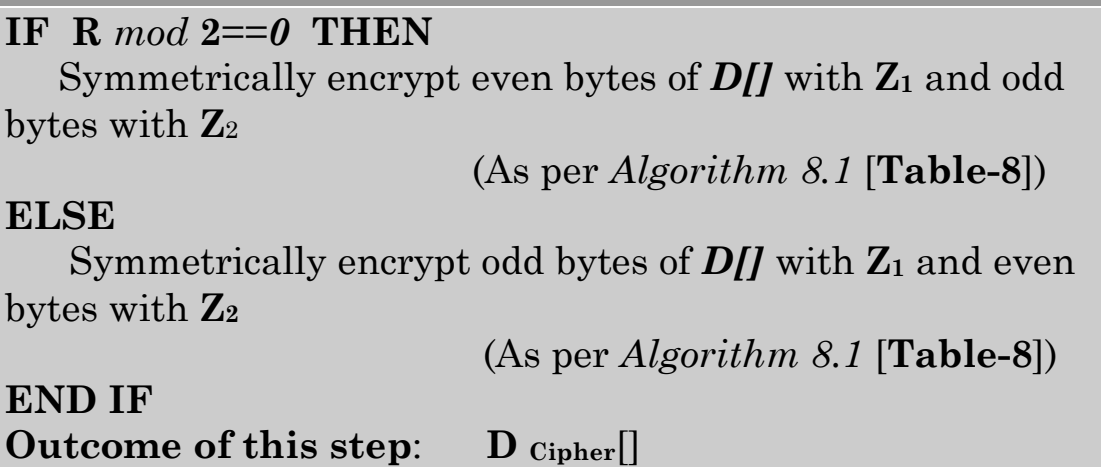 \\
\hline & 9 & $\begin{array}{l}\text { Encrypt the value of } \boldsymbol{R} \text { with the own private key to obtain } \boldsymbol{S} \\
\text { Outcome of this step: } \\
\boldsymbol{S}:=\boldsymbol{E}_{- \text {Sender }}(\boldsymbol{R})\end{array}$ \\
\hline
\end{tabular}




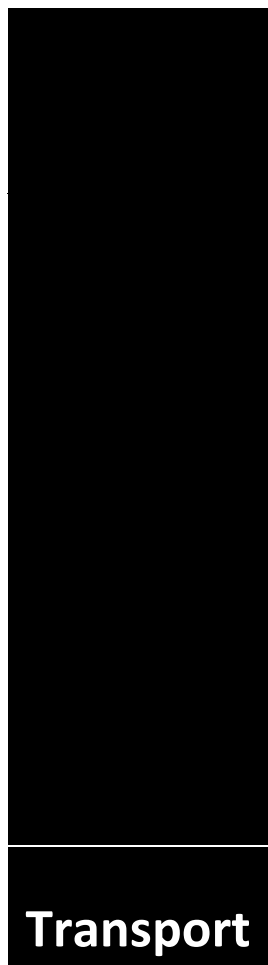

\section{Layer}

10 A DATA_COMM packet is formed in the application layer with the following fields

\begin{tabular}{|c|c|c|c|}
\hline Field Name & Field Position & $\begin{array}{l}\text { Field Size } \\
\text { (in Bytes) }\end{array}$ & $\begin{array}{l}\text { Field } \\
\text { Value }\end{array}$ \\
\hline FIELD TYPE & $1^{\text {st }}$ Byte & 1 Byte & $\begin{array}{c}\text { Calculated } \\
\text { according } \\
\text { to } \\
\text { Algorithm } \\
1 \\
\text { [TABLE- } \\
\text { 2] }\end{array}$ \\
\hline TIMESTAMP & $2^{\text {nd }}$ Byte $-9^{\text {th }}$ Byte & 8 Bytes & ts \\
\hline DATA_LEN & $\begin{array}{l}10^{\text {th }} \text { Byte- } 11^{\text {th }} \\
\text { Byte }\end{array}$ & 2 Bytes & $\begin{array}{c}\text { length }(D \\
\text { Cipher[I] }\end{array}$ \\
\hline DATA & $12^{\text {th }}$ Byte onwards & $\begin{array}{r}\text { length }(\boldsymbol{D} \\
\text { Cipher[] }\end{array}$ & D Cipher [] \\
\hline $\begin{array}{l}\text { SIGNATURE- } \\
\text { ALIAS }\end{array}$ & $\begin{array}{c}{\left[11+\text { length }\left(\mathrm{D}_{\text {cipher }}\right)\right]^{-}} \\
\text {th Byte onwards }\end{array}$ & VARIABLE & $S$ \\
\hline
\end{tabular}

11 The $\boldsymbol{O S L}$ layer packet is forwarded to the Transport layer. Since the packet comes from the $\boldsymbol{O S L}$, it is processed by the augmentation logic of transport layer. A TCP packet is created encapsulating the $\boldsymbol{O S L}$ packet as payload.

12 The value of the digest function is calculated for the TCP header bytes

Outcome of this step: $\quad \boldsymbol{h}:=\mathbf{g}(T C P$ header bytes $)$

13 Bytes of the field $\boldsymbol{D A T A} \boldsymbol{L} \boldsymbol{E N}$ (i.e. the $\mathbf{4}^{\text {th }}$ field) are encrypted with the symmetric key $\boldsymbol{h}$.

FOR $J=0$ to $D_{\text {Cipher.length }}$

$$
\mathrm{D}_{\text {Cipher }}[\boldsymbol{J}]:=\boldsymbol{E}(\boldsymbol{D} \text { Cipher }[\boldsymbol{J}], \boldsymbol{h})
$$

\section{Next $J$}

14 The TCP packet is transferred to the layer below, i.e. the Network Layer

\begin{tabular}{|c|c|}
\hline INPUT & $\begin{array}{ll}\text { a. } & \mathrm{D}[] \\
\text { b. } & \mathrm{R} \\
\text { c. } & \mathrm{Z}_{1} \\
\text { d. } & \mathrm{Z}_{2}\end{array}$ \\
\hline STEP & $\begin{array}{l}\text { D Cipher : }=\text { new } \text { byte }[\text { D.length }] \\
\text { FOR I=0 To D.length } \\
\quad \text { D Cipher }[\mathrm{I}]:=\mathrm{D}[\mathrm{I}] \Phi(\mathbf{R} \bmod 2==\mathbf{A N D} \mathbf{I} \bmod 2==\mathbf{\operatorname { m o d }}) ? \mathbf{Z}_{1}: \mathbf{Z}_{2} \\
\text { NEXT } I\end{array}$ \\
\hline Output & D Cipher \\
\hline
\end{tabular}


Table 9. Algorithm 9

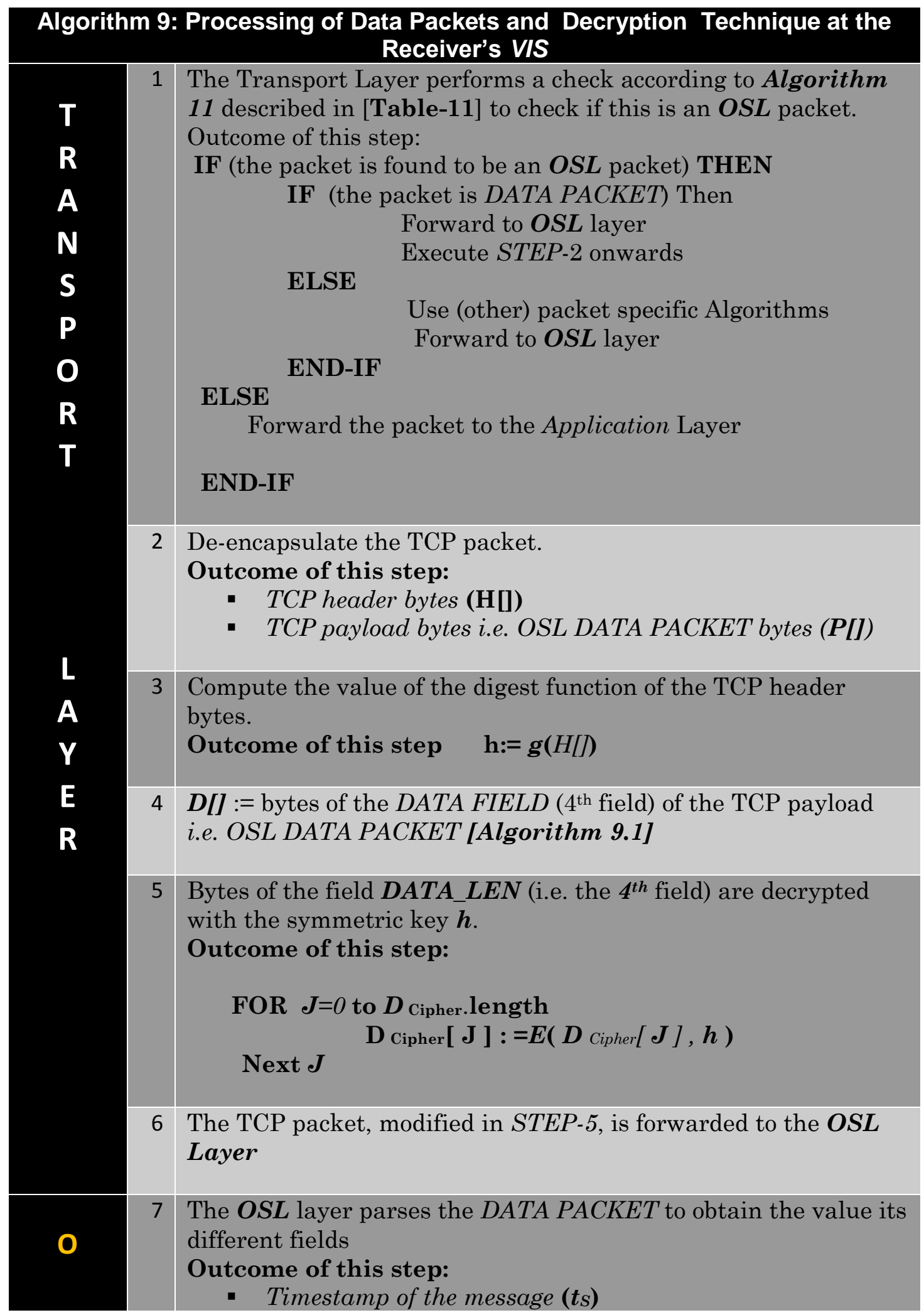




\begin{tabular}{|c|c|c|}
\hline $\mathbf{S}$ & & $\begin{array}{l}\text { - Data field bytes }(D[]) \\
\text { - } \quad \text { The Signature Alias }(S)\end{array}$ \\
\hline $\mathbf{L}$ & 8 & $\begin{array}{l}\text { Decrypt the value of the Signature Alias with the Sender's public } \\
\text { key. } \\
\text { Outcome of this step: } \\
\qquad:=E_{+S e n d e r}(\boldsymbol{S})\end{array}$ \\
\hline $\begin{array}{l}\mathrm{L} \\
\mathrm{A}\end{array}$ & 10 & 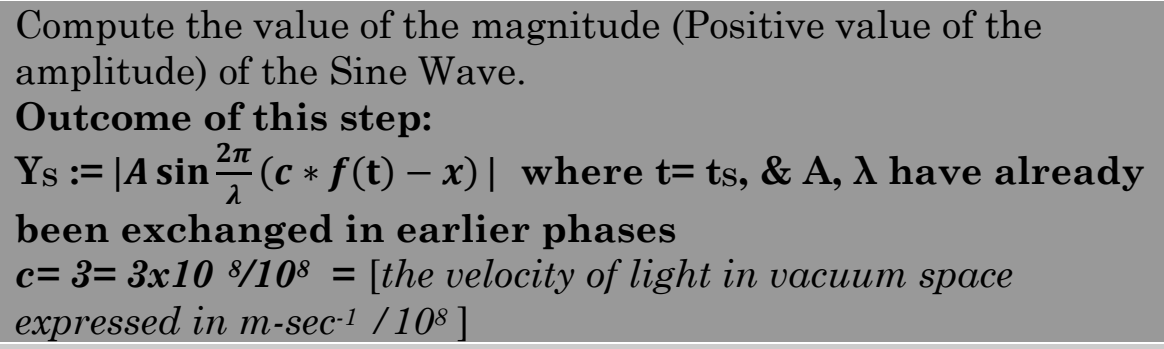 \\
\hline $\mathbf{E}$ & 10 & $\begin{array}{l}\text { The } \boldsymbol{p} \text {-function of the wavelength of the above Sine wave is } \\
\text { calculated } \\
\text { Outcome of this step: } \mathbf{W}:=\mathbf{p}(\boldsymbol{\lambda})\end{array}$ \\
\hline $\mathbf{R}$ & 11 & $\begin{array}{l}\text { Two one-time key-aliases }\left(Z_{1} \text { and } Z_{2}\right) \text { are calculated with } R, Y_{S} \\
\text { and } \boldsymbol{W} \text {. } \\
\text { Outcome of this step: } \quad Z_{1}:=\mathbf{R} \Phi \mathbf{Y}_{S} \text { and } Z_{2}:=\mathbf{R} \\
\Phi \mathbf{W}\end{array}$ \\
\hline & 12 & 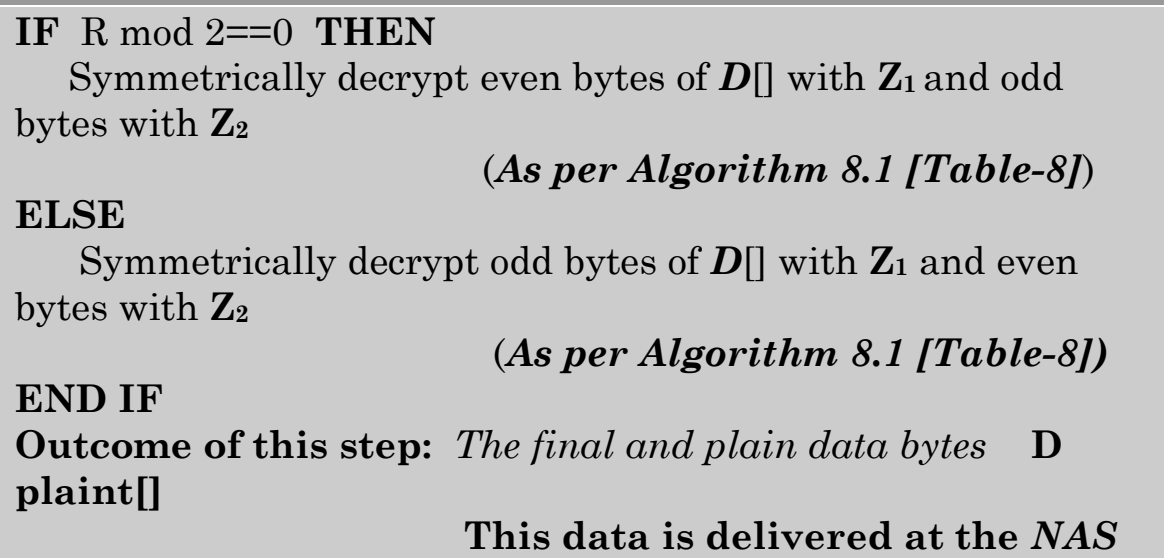 \\
\hline
\end{tabular}

\begin{tabular}{|c|c|}
\hline \multicolumn{2}{|r|}{ Input: The OSL DATA PACKET Bytes ( P[] ) } \\
\hline 1 & $X:=$ Value of the $10^{\text {th }}$ and $11^{\text {th }}$ Bytes \\
\hline 2 & $\begin{array}{l}\text { Since DATA_LEN field consists of the } 10^{\text {th }} \text { and } 11^{\text {th }} \text { bytes of this packet, } \\
\text { the value of the field DATA-LEN: }=X\end{array}$ \\
\hline 3 & $\begin{array}{l}\text { First } 11 \text { bytes accommodate the fields PACKET TYPE ( } 1 \text { BYTE), TIMESTAMP (11 BYTES) } \\
\text { and DATA-LEN } \\
\text { ( } 2 \text { BYTES). So, the DATA FIELD starts from the } 12^{\text {th }} \text { bytes onwards and continue till next } \\
\text { DATA-LEN bytes. }\end{array}$ \\
\hline 4 & $\begin{array}{l}\text { Hence, the data bytes are obtained as: } \\
D[]:=\text { new byte }[X] \\
\text { FOR } J=0 \text { TO } X\end{array}$ \\
\hline
\end{tabular}




$$
\begin{aligned}
& \mathrm{D}[\boldsymbol{J}]:=\mathrm{P}[\boldsymbol{J}+11] \\
& \text { NEXT } J
\end{aligned}
$$

\section{Table 10. String Parsing Algorithms}

\section{Algorithm 3.1. String Generation}

1. There is a common DELIMITER which both client and server know of

2. Input: $\boldsymbol{N}$ number of strings, where $\boldsymbol{N} \boldsymbol{\epsilon} \boldsymbol{I}^{+}$, DELIMITER

3. resultString:= " " // EMPTY String

4. For $\mathrm{I}=0$ to $\mathrm{N}-1$

$$
>\text { resultString }:=\text { concat }\left(\text { resultString, DELIMITER, } \mathrm{I}^{\text {th }}\right. \text { String) }
$$

Next I

5. Output:= resultString

\section{Algorithm-3.2: String Extraction Algorithm}

\section{Table-11: Algorithm-12}

\section{ALGORITHM 12: Check if inbound TCP Packet is an OSL packet}

Input A TCP Packet, it's header and payload bytes $(H[]$ and $P[])$

$1 \quad V:=$ The value of the first byte of the payload $=P[0]$

$2 T_{s}$ := Long value of next 8 bytes = longValue(P[1], P[2], P[3], P[4], P[5], P[6], P[7], $P[8])$

$3 \quad \mathrm{M}:=\mathrm{T}_{\mathrm{s}} \bmod \mathbf{3 2}$

$4 \quad B_{M}:=$ toBinary $(M) \equiv\left\{b_{4} b_{3} b_{2} b_{1} b_{0}\right\}$

$5 \quad B_{V}:=$ toBinary $(V) \equiv\left\{B_{7} B_{6} B_{5} B_{4} B_{3} B_{2} B_{1} B_{0}\right\}$

6 IF (first 5 bits from the LSB of $B_{M}$ and $B_{V}$ match) THEN

$X:=$ toDecimal $\left(B_{7} B_{6} B_{5}\right)$

IF $(X>=0$ AND $X<=4)$ THEN

Output: The packet is an OSL Packet of Type $X$ ELSE

Output: The packet is not an OSL packet END-IF

ELSE

END-IF

Output: The packet is not an OSL packet 
Table-12: Legends and Significance of terms

\begin{tabular}{|c|c|c|}
\hline $\begin{array}{l}\text { Serial } \\
\text { No. }\end{array}$ & Term/Legend & Description \\
\hline 1 & VIS & Virtual Internetworking Stack \\
\hline 2 & OSL (also, OSL layer) & Opaque Security Layer \\
\hline 3 & Client & $\begin{array}{l}\text { The VIS of a host that invites another VIS to } \\
\text { communicate }\end{array}$ \\
\hline 4 & Server & VIS which is invited by the client VIS \\
\hline 5 & $E_{+ \text {Server }}(X)$ & Encrypt/Decrypt $X$ with the public key of the Server \\
\hline 6 & $E_{- \text {Server }}(\mathbf{X})$ & Decrypt/Encrypt $X$ with the private key of the Server \\
\hline 7 & QR(aText) & Create a QR code off the String, aText \\
\hline 8 & $Q^{-1}(Q)$ & Decode a QR code and get the text \\
\hline 9 & Rand() or Random() & Generate a positive, random integer \\
\hline 10 & toBinary(x) & Convert a byte $\mathrm{x}$ (in decimal) to its binary equivalent \\
\hline 11 & $\begin{array}{l}\text { colorOf(img)/ } \\
\text { getColor(img) }\end{array}$ & $\begin{array}{l}\text { Get the color of an image, all of whose pixels have same } \\
\text { color (ARGB) }\end{array}$ \\
\hline 12 & Length(Q[]) / Len(Q[]) & Number of elements of the array, $Q$ \\
\hline
\end{tabular}

\subsection{Illustrations of sample packets}

Results and reports of the experiments carried out with the implementation of the VIS security model were duly logged. A few samples of the $O S L$ packets are presented in this section. [Table-23] shows a SESSION REQUEST Packet while the tables [Table-24] to [Table-27] present the four other types of packets defined by the $\boldsymbol{O S L}$. We analyze the bytes of the SESSION REQUEST packet presented in [Table-23]. The first byte of any of the five OSL packets represents the type of the packet, while the bytes $2^{\text {nd }}$ to $9^{\text {th }}$ represent the 8 -byte timestamp. The timestamp bytes, $\{0,0,1,66,39,-70,-11,-31\}$ represent the value 1383646033377 which is indicative of "Tue Nov 05 15:37:13 IST 2013". The packet-type field in [Table-23] contains the value 1 . Since the 5 LSBS contain the value: 1383646033377 $\bmod 32=1$, whereas the $3 M S B s$ contain the raw initial identifier assigned to the packet type (i.e. $O$ here); the value of the first field is computed to be $(\underline{000} \underline{00001})_{2}=1$.

Similarly, the value of the first byte of the challenge packet, shown in [Table-24] can be computed to be $(\underline{001} \underline{00001})_{2}=33$, according to Algorithm 1 [Table-2]

The public and private keys of the Server-side VIS that corresponds to performance analysis described in Sec. 3.3 are shown in [Table-28]. Samples of the color QR codes generated during creation of a SESSION REQUEST packet and creation of an $O S L$ CHALLENGE packet, as described in Algorithm 2 in [Table-3] and Algorithm 3 in [Table-4] are presented in [Figure-14].

\subsection{Encapsulation of the OSL packets}


The $O S L$ layer packets are, however, encapsulated within a $T C P$ packet. The $T C P$ packet is encapsulated within an $I P$ datagram and finally an $I P$ datagram is encapsulated in a Link layer frame, as shown in [Figure 13].

[Figure-15] shows the analysis of the headers belonging to the Transport layer, the Network Layer and the Link Layer (shown as an Ethernet header)

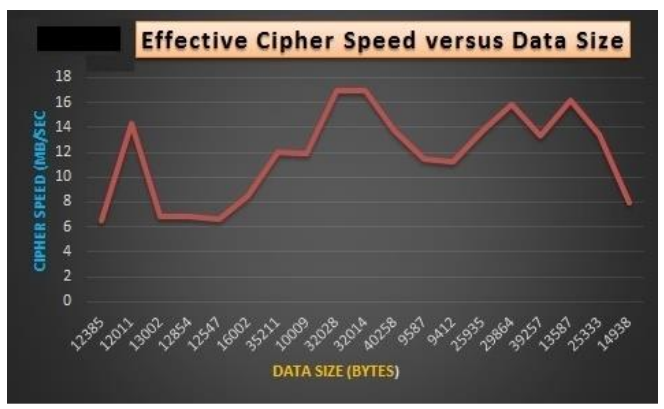

Fig.8: Effective Cipher Speed versus Data Size

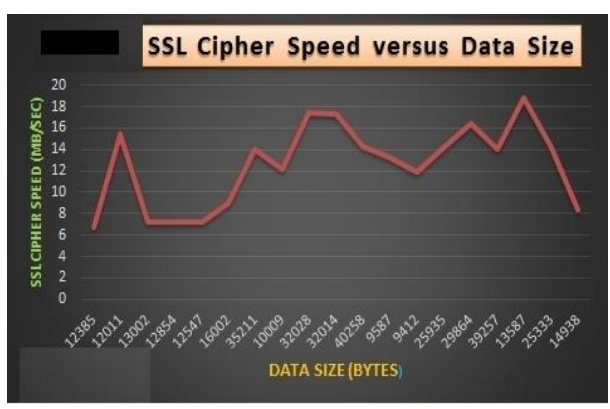

Fig. 9: SSL Cipher speed versus Data Size

\section{Performance analysis of the security model}

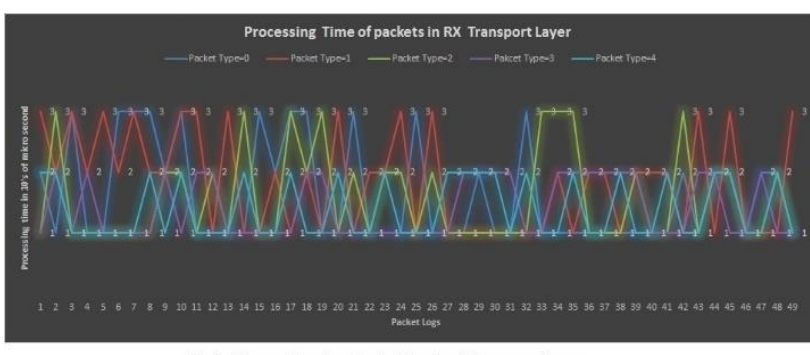

Fig.5 : Processing time in in Receiver Transport Layer

The security model of the Networking stack envisaged in this thesis, was implemented both on a Linux Kernel and on a Microsoft Windows Operating System. While the implementation was experimentally found to be responsive and scalable, every single event in the VIS implementation was logged for analysis of its performance and comparison of the security model with $S S L$ version 2. [Table-13] illustrates the processing performance of a SESSION REQUEST packet at a Sender-side VIS equipped with a $1.2 \mathrm{GHz}$ dual Core processor and $2 G B$ of physical memory. Though the $L O G$ contained about a million of records, the tables provided here have been abridged. Before presenting these tables and relevant graphs, however, the integrity of the entire $L O G$ with the abridged set of results presented with this article has been duly verified. In [Table-13] we find that a SESSION REQUEST packet

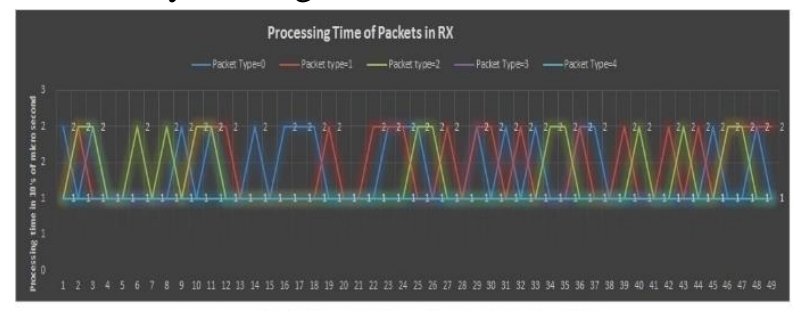

Fig. 6 : Processing Time of packets in Receiver VIS has an average processing time of $1,400 \mu \mathrm{sec}$ and $400 \mu \mathrm{sec}$ at the $O S L$ layer and the Transport Layer, respectively, in a VIS running on a $1.2 \mathrm{GHz}$ dual core processor and $2 \mathrm{~GB}$ of $R A M$. It is interesting to note that the standard deviation at the Transport Layer is $\boldsymbol{Z E R \boldsymbol { O }}$ while the standard deviation at the $O S L$ layer is $917.7 \mu \mathrm{sec}$. This is due to the fact that $O S L$ layer deals with generation of QR codes; and the time required to generate $\mathrm{QR}$ codes off different texts varies by considerably. Since the transport layer encrypts almost some fixed number of bytes with a symmetric key, $h=\boldsymbol{g}(T C P$ header) while processing a SESSION REQUEST packet as described in Algorithm 2 [Table 3], the process exhibits a standard deviation equal to zero $\mu \mathrm{sec}$. 
[Table-14], which shows the processing of a SESSION REQUEST packet at a Receiverside VIS, also suggests a zero standard deviation at the transport layer. The processing of three other types of $O S L$ packets used during the establishment of a secure session, are illustrated in the [Tables 15-20]. All the tables here are suggestive of consistent performance in the augmented transport layer. The variation of performance time in the $O S L$ layer, however, is acceptable as the standard deviation never exceeded $600 \mu \mathrm{sec}$ in average. Processing time of the five types of OSL packets in the Sender-side $O S L$ layer and the senderside transport layer are plotted in the graphs as shown in [Figure-3] and [Figure-4], respectively. Also, [Figure-5] and [Figure-6] present the processing time of these packets in the Transport layer and the OSL layer, respectively, of a receiver-side VIS.

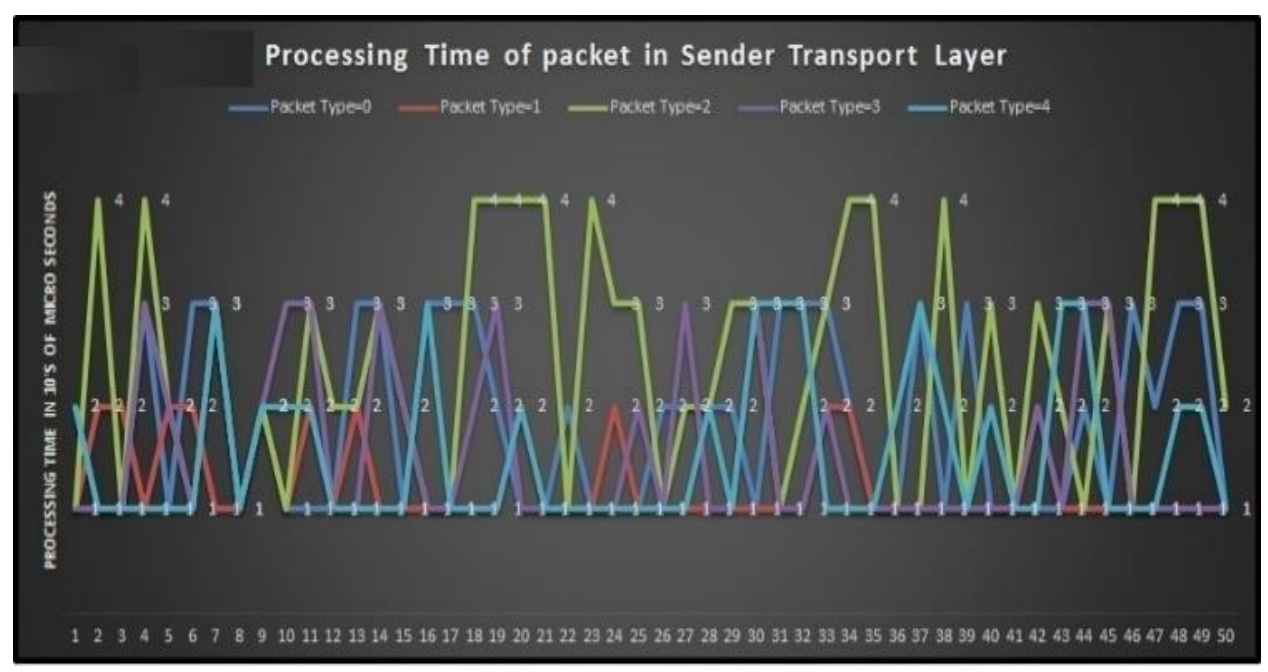

Fig.4 : Processing time in Sender Transport Layer

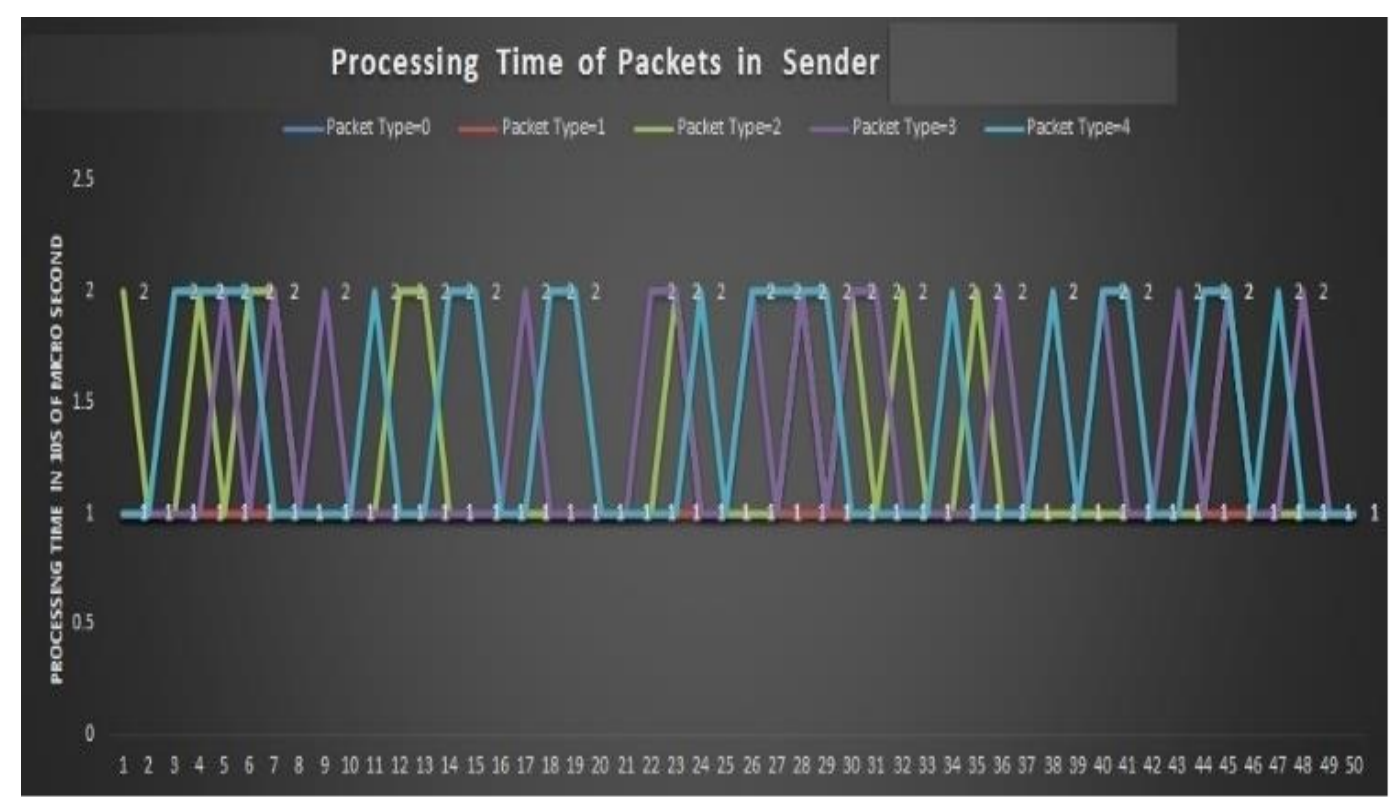

Fig.3 Processing Time at Sender VIS 
Table-13: Processing time of the Session Request packet in a sender-side VIS

\begin{tabular}{|c|c|c|c|c|c|c|c|}
\hline \multirow{2}{*}{$\begin{array}{l}\text { Packet } \\
\text { type } \\
\text { (Most } \\
\text { significant } \\
3 \text { bits) }\end{array}$} & \multicolumn{3}{|c|}{$\begin{array}{l}\text { (DOWNWARDS THE STACK) } \\
\text { TIMESTAMP IN THE VIS }\end{array}$} & \multicolumn{2}{|c|}{$\begin{array}{l}\text { Elapsed Time } \\
\text { interval }(\Delta t) \text { in } \\
\text { milliseconds }\end{array}$} & \multicolumn{2}{|c|}{$\begin{array}{c}\text { Processing Time } \\
\text { in } \mu \text { sec } \\
=\Delta t-\text { Logging Delay } \\
\text { (0.6 milliseconds) }\end{array}$} \\
\hline & Application Layer & OSL Layer & Transport Layer & $\begin{array}{c}\text { OSL } \\
\text { Layer }\end{array}$ & $\begin{array}{c}\text { Transport } \\
\text { Layer }\end{array}$ & $\begin{array}{c}\text { OSL } \\
\text { Layer }\end{array}$ & $\begin{array}{c}\text { Transport } \\
\text { Layer }\end{array}$ \\
\hline $0 \times 00$ & $1,383,544,080,111$ & $1,383,544,080,113$ & $1,383,544,080,114$ & 2 & 1 & $1,400.0$ & 400.0 \\
\hline $0 \times 00$ & $1,383,544,080,111$ & $1,383,544,080,112$ & $1,383,544,080,113$ & 1 & 1 & 400.0 & 400.0 \\
\hline $0 \times 00$ & $1,383,544,080,111$ & $1,383,544,080,112$ & $1,383,544,080,113$ & 1 & 1 & 400.0 & 400.0 \\
\hline $0 \times 00$ & $1,383,544,080,111$ & $1,383,544,080,114$ & $1,383,544,080,115$ & 3 & 1 & $2,400.0$ & 400.0 \\
\hline $0 \times 00$ & $1,383,544,080,111$ & $1,383,544,080,112$ & $1,383,544,080,113$ & 1 & 1 & 400.0 & 400.0 \\
\hline $0 \times 00$ & $1,383,544,080,111$ & $1,383,544,080,114$ & $1,383,544,080,115$ & 3 & 1 & $2,400.0$ & 400.0 \\
\hline $0 \times 00$ & $1,383,544,080,111$ & $1,383,544,080,114$ & $1,383,544,080,115$ & 3 & 1 & $2,400.0$ & 400.0 \\
\hline $0 \times 00$ & $1,383,544,080,111$ & $1,383,544,080,112$ & $1,383,544,080,113$ & 1 & 1 & 400.0 & 400.0 \\
\hline $0 \times 00$ & $1,383,544,080,111$ & $1,383,544,080,113$ & $1,383,544,080,114$ & 2 & 1 & $1,400.0$ & 400.0 \\
\hline $0 \times 00$ & $1,383,544,080,111$ & $1,383,544,080,112$ & $1,383,544,080,113$ & 1 & 1 & 400.0 & 400.0 \\
\hline $0 \times 00$ & $1,383,544,080,111$ & $1,383,544,080,112$ & $1,383,544,080,113$ & 1 & 1 & 400.0 & 400.0 \\
\hline $0 \times 00$ & $1,383,544,080,112$ & $1,383,544,080,113$ & $1,383,544,080,114$ & 1 & 1 & 400.0 & 400.0 \\
\hline $0 \times 00$ & $1,383,544,080,112$ & $1,383,544,080,115$ & $1,383,544,080,116$ & 3 & 1 & $2,400.0$ & 400.0 \\
\hline $0 \times 00$ & $1,383,544,080,112$ & $1,383,544,080,115$ & $1,383,544,080,116$ & 3 & 1 & $2,400.0$ & 400.0 \\
\hline $0 \times 00$ & $1,383,544,080,112$ & $1,383,544,080,113$ & $1,383,544,080,114$ & 1 & 1 & 400.0 & 400.0 \\
\hline $0 \times 00$ & $1,383,544,080,112$ & $1,383,544,080,115$ & $1,383,544,080,116$ & 3 & 1 & $2,400.0$ & 400.0 \\
\hline $0 \times 00$ & $1,383,544,080,112$ & $1,383,544,080,115$ & $1,383,544,080,116$ & 3 & 1 & $2,400.0$ & 400.0 \\
\hline $0 \times 00$ & $1,383,544,080,112$ & $1,383,544,080,115$ & $1,383,544,080,116$ & 3 & 1 & $2,400.0$ & 400.0 \\
\hline $0 \times 00$ & $1,383,544,080,112$ & 1,383,544,080,114 & 1,383,544,080,115 & 2 & 1 & $1,400.0$ & 400.0 \\
\hline & & & & Average & & 1400 & 400 \\
\hline & & & & STD. & & 917.7 & 0.0 \\
\hline
\end{tabular}

- The results here correspond to a VIS running on a $1.2 \mathrm{GHZ}$ dual core processor and 2 GB memory. 
Table-14: Processing time of SESSION REQUEST packet at a RECEIVER-SIDE VIS

\begin{tabular}{|c|c|c|c|c|c|c|c|}
\hline \multirow{2}{*}{$\begin{array}{c}\begin{array}{c}\text { Packet } \\
\text { Type }\end{array} \\
3 \text { most } \\
\text { significa } \\
n t \\
\text { bits }\end{array}$} & \multicolumn{3}{|c|}{ Entry time timestamp in the stack } & \multicolumn{2}{|c|}{$\begin{array}{l}\text { Elapsed Time } \\
\text { interval }(\Delta t) \text { in } \\
\text { milliseconds }\end{array}$} & \multicolumn{2}{|c|}{$\begin{array}{c}\text { Processing Time } \\
\text { in } \mu \text { sec } \\
=\Delta \mathrm{t}-\text { Logging Delay } \\
\text { (0.6 milliseconds) }\end{array}$} \\
\hline & Transport Layer & OSL Layer & Application Layer & $\begin{array}{c}\text { Transport } \\
\text { Layer }\end{array}$ & OSL Layer & $\begin{array}{c}\text { Transport } \\
\text { Layer }\end{array}$ & $\begin{array}{l}\text { VNS } \\
\text { Layer }\end{array}$ \\
\hline $0 \times 00$ & $1,383,544,234,504$ & $1,383,544,234,505$ & $1,383,544,234,507$ & 1 & 2 & 400.00 & $1,400.00$ \\
\hline $0 \times 00$ & $1,383,544,234,504$ & $1,383,544,234,505$ & $1,383,544,234,506$ & 1 & 1 & 400.00 & 400.00 \\
\hline $0 \times 00$ & $1,383,544,234,506$ & $1,383,544,234,507$ & $1,383,544,234,509$ & 1 & 2 & 400.00 & $1,400.00$ \\
\hline $0 \times 00$ & $1,383,544,234,504$ & $1,383,544,234,505$ & $1,383,544,234,506$ & 1 & 1 & 400.00 & 400.00 \\
\hline $0 \times 00$ & $1,383,544,234,504$ & $1,383,544,234,505$ & $1,383,544,234,506$ & 1 & 1 & 400.00 & 400.00 \\
\hline $0 \times 00$ & $1,383,544,234,506$ & $1,383,544,234,507$ & $1,383,544,234,508$ & 1 & 1 & 400.00 & 400.00 \\
\hline $0 \times 00$ & $1,383,544,234,506$ & $1,383,544,234,507$ & $1,383,544,234,508$ & 1 & 1 & 400.00 & 400.00 \\
\hline $0 \times 00$ & $1,383,544,234,506$ & $1,383,544,234,507$ & $1,383,544,234,508$ & 1 & 1 & 400.00 & 400.00 \\
\hline $0 \times 00$ & $1,383,544,234,505$ & $1,383,544,234,506$ & $1,383,544,234,508$ & 1 & 2 & 400.00 & $1,400.00$ \\
\hline $0 \times 00$ & $1,383,544,234,506$ & $1,383,544,234,507$ & $1,383,544,234,508$ & 1 & 1 & 400.00 & 400.00 \\
\hline $0 \times 00$ & $1,383,544,234,504$ & $1,383,544,234,505$ & $1,383,544,234,507$ & 1 & 2 & 400.00 & $1,400.00$ \\
\hline $0 \times 00$ & $1,383,544,234,504$ & $1,383,544,234,505$ & $1,383,544,234,506$ & 1 & 1 & 400.00 & 400.00 \\
\hline $0 \times 00$ & $1,383,544,234,504$ & $1,383,544,234,505$ & $1,383,544,234,506$ & 1 & 1 & 400.00 & 400.00 \\
\hline $0 \times 00$ & $1,383,544,234,504$ & $1,383,544,234,505$ & $1,383,544,234,507$ & 1 & 2 & 400.00 & $1,400.00$ \\
\hline $0 \times 00$ & $1,383,544,234,506$ & $1,383,544,234,507$ & $1,383,544,234,508$ & 1 & 1 & 400.00 & 400.00 \\
\hline $0 \times 00$ & $1,383,544,234,505$ & $1,383,544,234,506$ & $1,383,544,234,508$ & 1 & 2 & 400.00 & $1,400.00$ \\
\hline $0 \times 00$ & $1,383,544,234,507$ & $1,383,544,234,508$ & $1,383,544,234,510$ & 1 & 2 & 400.00 & $1,400.00$ \\
\hline $0 \times 00$ & $1,383,544,234,507$ & $1,383,544,234,508$ & $1,383,544,234,510$ & 1 & 2 & 400.00 & $1,400.00$ \\
\hline $0 \times 00$ & $1,383,544,234,505$ & $1,383,544,234,506$ & $1,383,544,234,507$ & 1 & 1 & 400.00 & 400.00 \\
\hline $0 \times 00$ & $1,383,544,234,505$ & $1,383,544,234,506$ & $1,383,544,234,507$ & 1 & 1 & 400.00 & 400.00 \\
\hline & & & & Average & & 400.00 & 800.00 \\
\hline & & & & STD. & & 0 & 502.6247 \\
\hline
\end{tabular}

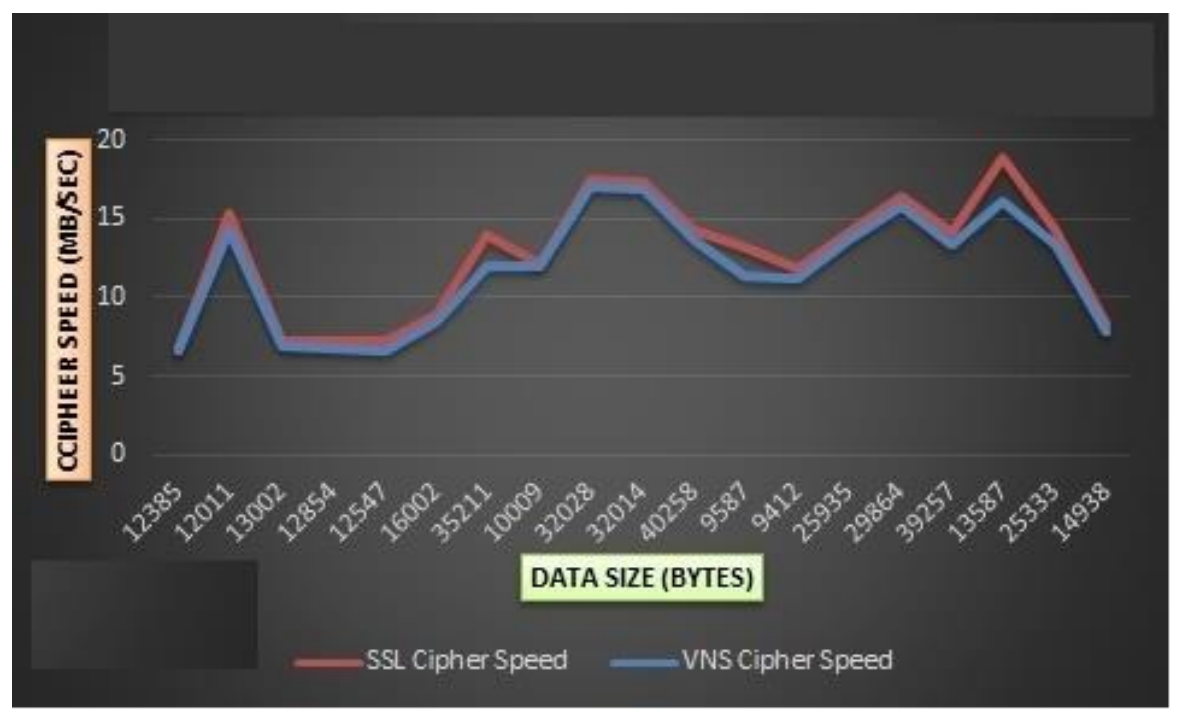

Fig, 10: Cipher speed versus Data size (Comparison curve) 


\subsection{Comparison with the performance of SSL}

The author carried out real time experiments to compare the performance of the security

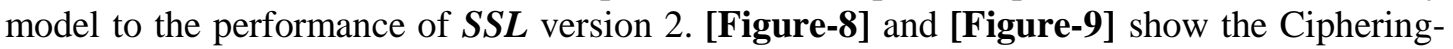
speed $(\mathrm{MB} / \mathrm{sec})$ versus data size (Bytes) graphs obtained with the same set of data processed by, a VIS implementation and the Secure Socket Layer (SSL version 2),respectively. In order to avoid performance lags due to heterogeneity of Hardware (like, Processor speed, memory etc.), same Hardware configuration was used while carrying out the experiments for this comparison. [Figure-10] presents the graphs for both VIS and SSL together. The results, however, proved the supremacy of the SSL over the VIS security model envisaged in this thesis as far as speed was concerned. But, the little bit of performance lag of the VIS model is acceptable for situations where security and flexibility demand more proprietary-ness than just performance. A secured system is secure as long as its architecture is not exposed to the world. Sometimes, we trust neither our ISP nor anybody else, depending on the sensitivity of the information that we communicate over Internet. Defense and Intelligence Bureau of a country cannot trust an ISP and there must be sniffers all around. Routers, for example, pass IP datagrams across the Internet and some of these routers might have some intention or other to sniff packets from a particular source. The model proposed in this thesis is strongly recommended to befool these evil routers and gateways. As appears to these sniffers, all packets from a VIS host are just valid IP datagram. If a gateway pushes these datagrams upward its TCP/IP stack to make out something meaningful, it will simply fail; because, its Internetworking stack is a standard stack and does not comply with the OSL and the augmented transport layer of the VIS model.

\subsection{Flexibility and opacity provided by the proposed VIS model}

In the VIS model discussed in this thesis, flexibility and opacity go hand-in-hand. The thesis recommends just a security model and not a standard, concrete implementation. It strongly prescribes proprietary security mechanisms in sectors such as Defense, space research, agencies dealing with highly valuable and viable IPR documents. The VIS offers the flexibility of Internetworking because it does not dig up the Network layer, lest the flexibility of Internetworking is lost. On the other hand, opacity prevails in the transport layer onwards. So, as appears to an evil router or a compromised gateway, the Network layer seems to deal with valid IP datagrams but the augmented rules injected in the transport layer and introduction of a proprietary $O S L$ layer in the VIS make it very difficult for the sniffers and a Man-In-Middle attacker to succeed. The VIS itself is very flexible to offer proprietary security, because it suggests what to do, but not how to achieve the ciphering techniques. An organization that might use this VIS security model, need not adhere to any strict cryptographic algorithm; rather any standard and/or proprietary cryptographic technique or a permutation of techniques can be used.

The maximum degree of flexibility is offered towards using a third party software. The introduction of the $O S L$ layer and the augmentation of the transport layer and their respective functional architecture need not be revealed to a third party software vendor. This is an added advantage to a software vendor consulted for rapid development of an application software plus it does not require an Organization to trust and compromise the proprietary security mechanism to a third party vendor. 


\subsection{Network Access Point}

All the applications running on an Operating System do not require same level of security. For example, one becomes more concerned about cyber security while Internet-banking than while on a casual chat for social networking. The VIS security model was conceptualized keeping this in mind. An employee of an organization that uses the VIS security model, may use an application on her computer which demands lesser security on the Internet than certain organizational applications.

$\boldsymbol{N A P}$ (Network Access Point) is basically a service access point offered by the $\boldsymbol{O S L}$ layer. [Figure-11] shows the logical position of the Network Access Point (NAP) in a Virtual Internetworking Stack.

All the applications that need to access Network must tap-in here to access the Virtual Internet Stack. The transport layer of the VIS is such augmented that:

a) In the sender-side, packet that come down from the OSL layer must be processed by the augmented transport layer logic. All the packets that come directly from the application layer, are not processed by the augmentation logic and are forwarded down to the standard transport layer of the TCP/IP stack.

b) In the receiver-side, packets that are recognized by the transport layer to belong to any of the five packet types defined by the $O S L$, are processed accordingly by the augmented transport layer logic and are handed over to the $O S L$ layer. Otherwise, a normal (Non-OSL type) packet is processed by the standard transport layer logic of the TCP/IP stack and are handed over directly to the application layer.

Network Access Point is a Service Access Point that filters unwanted applications and deny service to a non-authenticated application. Three important rules to note about an $\boldsymbol{N A P}$ are:

a) It offers Network service to the applications that need to access network over the VIS model. All the applications that needs to use VIS must hook-onto the NAP.

Algorithm 10 [Table-21] shows how a packet is processed at the NAP in a VIS.

[Figure-12] illustrates the abstraction provided by the $O S L$ and the role of an NAP.

b) It authenticates an application that seeks to avail network access. If authentication fails it can either allow Internet connection over standard TCP/IP stack, or can deny any network access. These rules, however, may be set by the system administrator of an organization as the organizational policies demand.

If authentication succeeds, it allows an application to use and communicate over the VIS security model.

Algorithm 11 [Table-21] shows how an application is authenticated at the NAP for being granted access to the VIS model.

c) It is very important to note that an application cannot access the standard TCP/IP stack and the Virtual Internetworking Stack simultaneously. If an application is already using the VIS, all the communication it makes over the Internet must be via VIS only. 
LOGICAL POSITION OF THE NETWORK ACCESS POINT IN A VIS

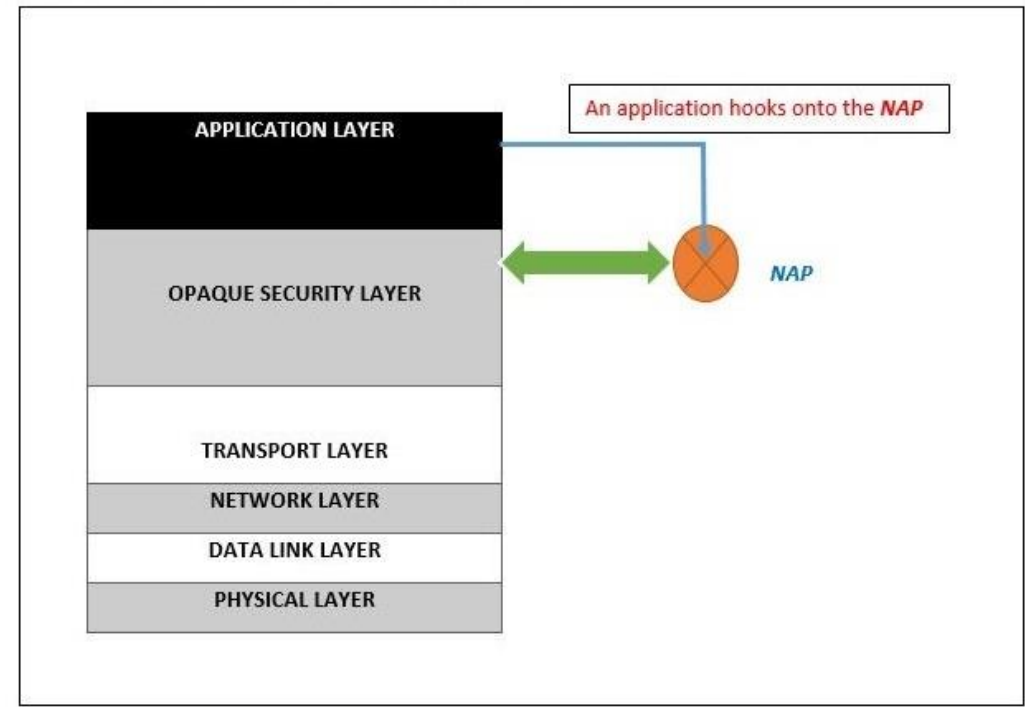

Fig.11: Posotion of the NAP inside VIS

THE ABSTRACTION PROVIDED BY THE OSL Layer and the NAP

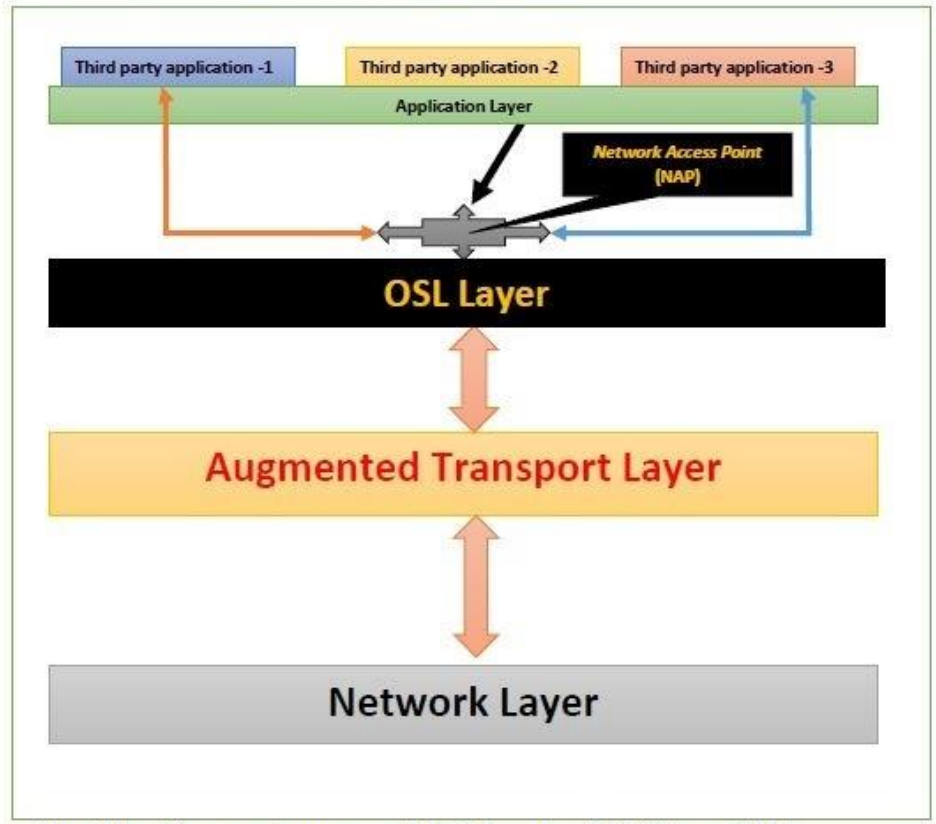

Fig.12: Abstraction provided by the NAP in a VIS 
Table-21. Network Access Point and Packet Processing in a VIS

\section{ALGORITHM 10: PROCESSING OF PACKET AT THE SENDER-SIDE VIS}

\begin{tabular}{|c|c|}
\hline APPLICATION & Application Layer generates Application data to be sent across Internet \\
\hline $\begin{array}{l}\text { NETWORK } \\
\text { ACCESS }\end{array}$ & $\begin{array}{l}\text { IF (App needs VIS) THEN } \\
\text { - App hooks onto the Network Access Point } \\
\text { Network Access Point must Authenticate the App's } \\
\text { signature [Algorithm 11] } \\
\text { IF (Authentication Successful) THEN } \\
\text { ELSE The Application Data is passed to the OSL Layer } \\
\text { END-IF } \\
\text { ELSE The Network Access (VIS) is denied } \\
\text { END-IF }\end{array}$ \\
\hline $\begin{array}{l}\text { L } \\
\text { A } \\
Y \\
\text { E } \\
\text { R }\end{array}$ & $\begin{array}{l}\text { OSL-Layer processing takes place. } \\
\text { EITHER } \\
\text { A secure connection is set up following the 4-phase session } \\
\text { establishment } \\
\text { OR } \\
\text { session } \\
\text { The OSL packets are handed over to the Transport Layer in both the cases } \\
\text { above. }\end{array}$ \\
\hline $\begin{array}{l}T \\
R \\
A \\
N \\
S \\
P \\
O \\
R \\
T\end{array}$ & $\begin{array}{l}\text { The Transport layer receives a packet } \\
\text { IF (The packet comes from the OSL Layer) THEN } \\
\text { ELSE } \\
\text { - Process the OSL Packet using augmentation logic } \\
\text { standardization of a normal TCP/IP stack } \\
\text { FND-IF }\end{array}$ \\
\hline $\begin{array}{l}\text { Network } \\
\text { Layer }\end{array}$ & $\begin{array}{l}\text { The Network layer has no clue as to the upper layers } \\
\text { and that is why Internetworking is not disturbed }\end{array}$ \\
\hline
\end{tabular}



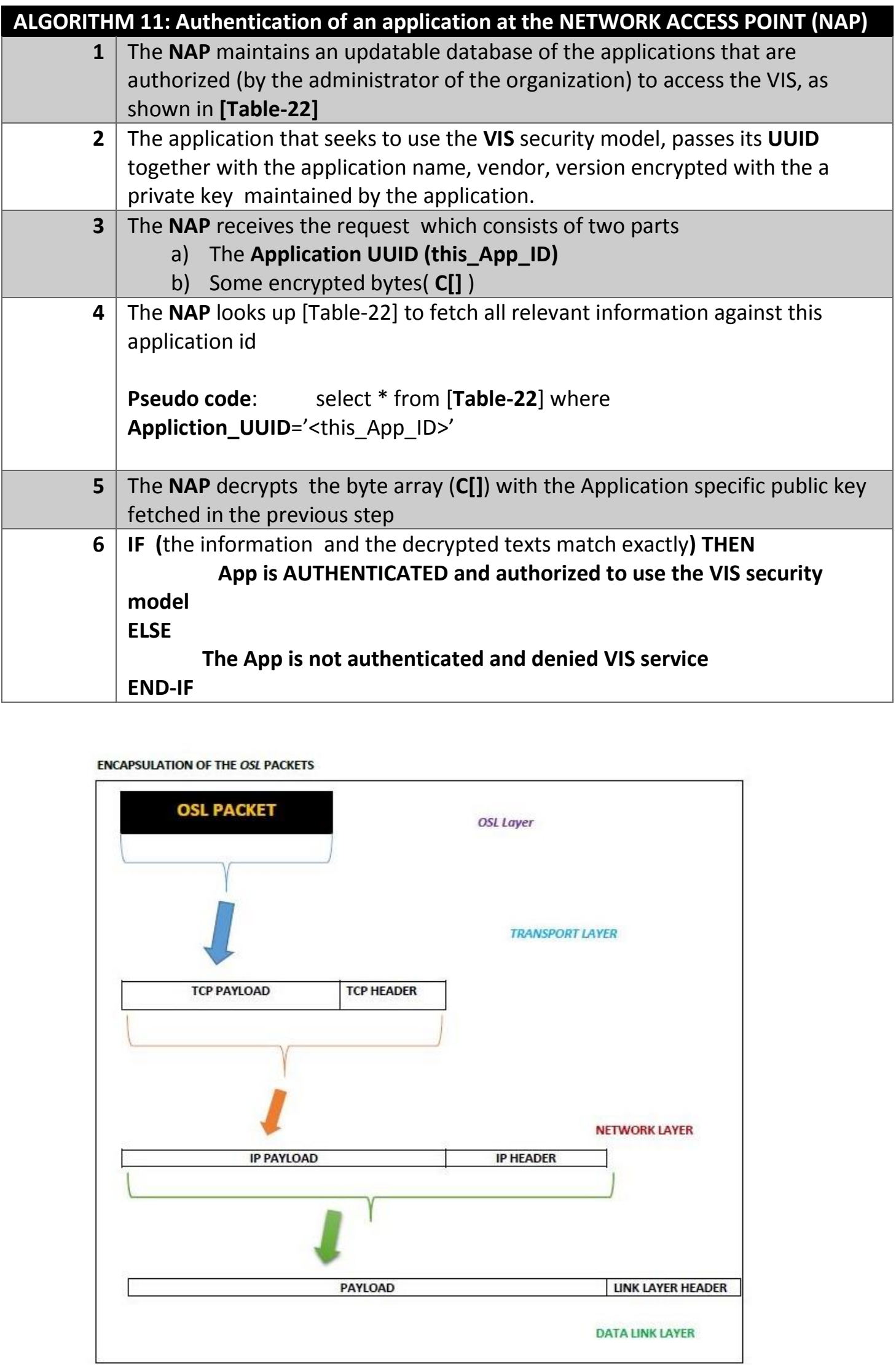

Fig. 13 : Encapsulation of OSL Packets 


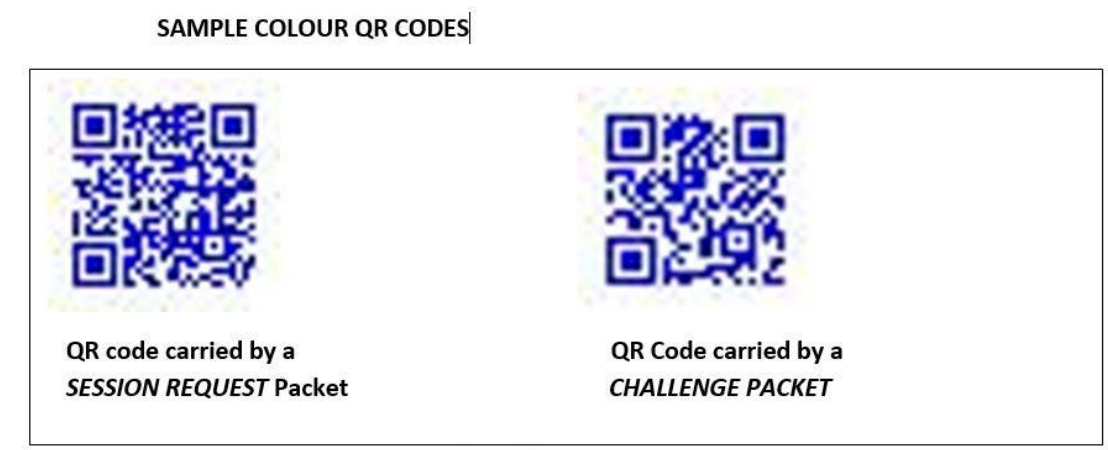

Fig.14: Samples of Color QR codes
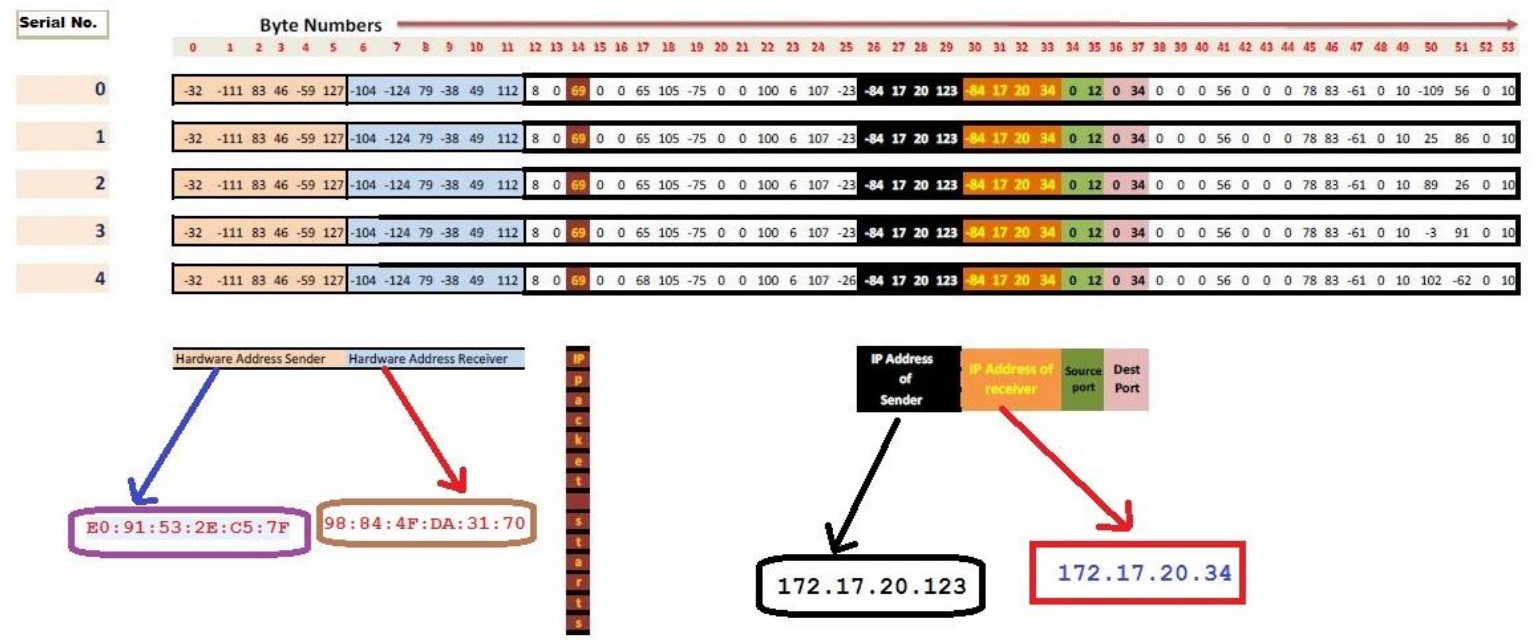

Fig.15: Layerwise Analysis of Headers down the Virtial Internetworking Stack

3.3.2 Benefits of NAP: Let us assume that a computer in an organization runs a number of applications among which only the applications $\boldsymbol{A}$ and $\boldsymbol{X}$ are compatible to the VIS model. We also assume that $\boldsymbol{X}$ is developed by a vendor who had some intention or other to write some Trojans to leak out some information. Initially the applications $\boldsymbol{A}$ and $\boldsymbol{X}$ are allowed to access the Network, because they are both authenticated and authorized to access the VIS. Now, the Application- $\boldsymbol{X}$ has some Trojan codes that were intended to leak out certain information from the computer to a remote enemy server. While Application- $\boldsymbol{X}$ executes as desired, in background it keeps sending certain information to a remote enemy server.

But, since it is hooked onto the NAP to access the VIS, all the communication application$\mathrm{X}$ can make across Internet, must be as per the VIS. Now, the enemy server that expects some information the spyware, cannot find anything meaningful at all; because, this server uses a TCP/IP stack which does not comply with a VIS communication. Trojans attacks in a VIS model thus run into vain. 


\section{Results:}

Table-15. Processing time of the challenge packet in the sender-side VIS

\begin{tabular}{|c|c|c|c|c|c|c|c|}
\hline \multirow{2}{*}{$\begin{array}{c}\text { Packet } \\
\text { Type }\end{array}$} & \multicolumn{3}{|c|}{$\begin{array}{l}\text { (DOWNWARD THE STACK) } \\
\text { TIMESTAMP IN THE VIS }\end{array}$} & \multicolumn{2}{|c|}{$\begin{array}{c}\text { Elapsed Time } \\
\text { interval }(\Delta t) \\
\text { in milliseconds }\end{array}$} & \multicolumn{2}{|c|}{$\begin{array}{c}\text { Processing } \\
\text { Time in } \mu \mathrm{sec} \\
=\Delta \mathrm{t} \text { - Logging } \\
\text { Delay (0.6 } \\
\text { milliseconds) }\end{array}$} \\
\hline & $\begin{array}{l}\text { Application } \\
\text { Layer }\end{array}$ & OSL Layer & $\begin{array}{c}\text { Transport } \\
\text { Layer }\end{array}$ & $\begin{array}{c}\text { OSL } \\
\text { Laye } \\
r\end{array}$ & $\begin{array}{l}\text { Transpo } \\
\text { rt Layer }\end{array}$ & $\begin{array}{c}\text { OSL } \\
\text { Laye } \\
r\end{array}$ & $\begin{array}{l}\text { Transpo } \\
\text { rt Layer }\end{array}$ \\
\hline $0 \times 01$ & $1,383,544,840,322$ & $1,383,544,840,323$ & $1,383,544,840,325$ & 1 & 2 & 400 & 1400 \\
\hline $0 \times 01$ & $1,383,544,840,322$ & $1,383,544,840,326$ & $1,383,544,840,327$ & 4 & 1 & $\begin{array}{r}340 \\
0\end{array}$ & 400 \\
\hline $0 \times 01$ & $1,383,544,840,322$ & $1,383,544,840,323$ & $1,383,544,840,324$ & 1 & 1 & 400 & 400 \\
\hline $0 \times 01$ & $1,383,544,840,322$ & $1,383,544,840,326$ & $1,383,544,840,328$ & 4 & 2 & $\begin{array}{r}340 \\
0\end{array}$ & 1400 \\
\hline $0 \times 01$ & $1,383,544,840,322$ & $1,383,544,840,324$ & $1,383,544,840,325$ & 2 & 1 & $\begin{array}{r}140 \\
0\end{array}$ & 400 \\
\hline $0 \times 01$ & $1,383,544,840,322$ & $1,383,544,840,323$ & $1,383,544,840,325$ & 1 & 2 & 400 & 1400 \\
\hline $0 \times 01$ & $1,383,544,840,322$ & $1,383,544,840,325$ & $1,383,544,840,327$ & 3 & 2 & $\begin{array}{r}240 \\
0 \\
\end{array}$ & 1400 \\
\hline $0 \times 01$ & $1,383,544,840,323$ & $1,383,544,840,324$ & $1,383,544,840,325$ & 1 & 1 & 400 & 400 \\
\hline $0 \times 01$ & $1,383,544,840,323$ & $1,383,544,840,325$ & $1,383,544,840,326$ & 2 & 1 & $\begin{array}{r}140 \\
0\end{array}$ & 400 \\
\hline $0 \times 01$ & $1,383,544,840,323$ & $1,383,544,840,324$ & $1,383,544,840,325$ & 1 & 1 & 400 & 400 \\
\hline $0 \times 01$ & $1,383,544,840,323$ & $1,383,544,840,326$ & $1,383,544,840,327$ & 3 & 1 & $\begin{array}{r}240 \\
0 \\
\end{array}$ & 400 \\
\hline $0 \times 01$ & $1,383,544,840,323$ & $1,383,544,840,325$ & $1,383,544,840,327$ & 2 & 2 & $\begin{array}{r}140 \\
0\end{array}$ & 1400 \\
\hline $0 \times 01$ & $1,383,544,840,323$ & $1,383,544,840,325$ & $1,383,544,840,327$ & 2 & 2 & $\begin{array}{r}140 \\
0\end{array}$ & 1400 \\
\hline $0 \times 01$ & $1,383,544,840,323$ & $1,383,544,840,326$ & $1,383,544,840,327$ & 3 & 1 & $\begin{array}{r}240 \\
0\end{array}$ & 400 \\
\hline $0 \times 01$ & $1,383,544,840,323$ & $1,383,544,840,325$ & $1,383,544,840,326$ & 2 & 1 & $\begin{array}{r}140 \\
0\end{array}$ & 400 \\
\hline $0 \times 01$ & $1,383,544,840,323$ & $1,383,544,840,324$ & $1,383,544,840,325$ & 1 & 1 & 400 & 400 \\
\hline $0 \times 01$ & $1,383,544,840,323$ & $1,383,544,840,324$ & $1,383,544,840,325$ & 1 & 1 & 400 & 400 \\
\hline $0 \times 01$ & $1,383,544,840,323$ & $1,383,544,840,327$ & $1,383,544,840,328$ & 4 & 1 & $\begin{array}{r}340 \\
0\end{array}$ & 400 \\
\hline $0 \times 01$ & $1,383,544,840,323$ & $1,383,544,840,327$ & $1,383,544,840,328$ & 4 & 1 & $\begin{array}{r}340 \\
0\end{array}$ & 400 \\
\hline $0 \times 01$ & $1,383,544,840,323$ & $1,383,544,840,327$ & $1,383,544,840,328$ & 4 & 1 & $\begin{array}{r}340 \\
0\end{array}$ & 400 \\
\hline
\end{tabular}




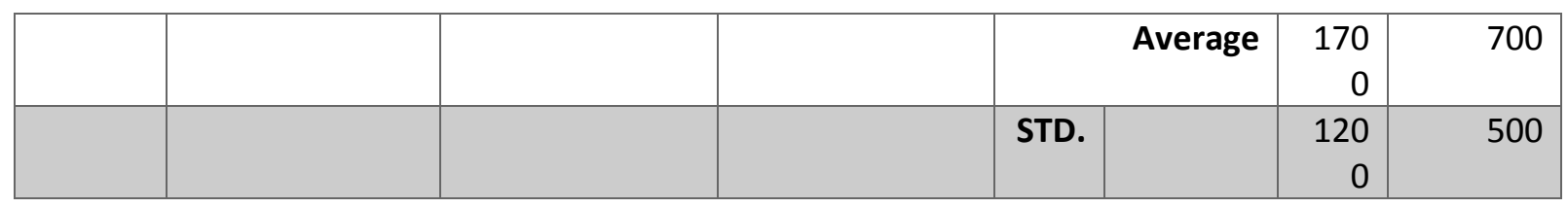

\section{Table 16. PROCESSING TIME OF THE CHALLENGE PACKET IN THE RECEIVER-SIDE VIS}

\begin{tabular}{|c|c|c|c|c|c|c|c|}
\hline $\begin{array}{l}\text { Packet } \\
\text { Type }\end{array}$ & & $\begin{array}{l}\text { UPWARD THE STACK } \\
\text { ESTAMP IN RECEIVER }\end{array}$ & - VIS & $\begin{array}{c}\text { Elapsed } \\
\text { interval ( } \\
\text { milliseco }\end{array}$ & $\begin{array}{l}\text { ime } \\
\text { at) in } \\
\text { nds }\end{array}$ & $\begin{array}{r}\text { Process } \\
\text { ( in } \\
=\Delta \mathrm{t}-\mathrm{Log} \\
(\mathbf{0 . 6} \mathrm{mil}\end{array}$ & $\begin{array}{l}\text { ing Time } \\
\text { sec) } \\
\text { ing Delay } \\
\text { seconds) }\end{array}$ \\
\hline 3 MSB & Transport Layer & OSL Layer & Application Layer & $\begin{array}{l}\text { Transport } \\
\text { Layer }\end{array}$ & $\begin{array}{l}\text { OSL } \\
\text { Layer }\end{array}$ & $\begin{array}{l}\text { Transport } \\
\text { Layer }\end{array}$ & OSL Layer \\
\hline $0 \times 01$ & $1,383,544,884,133$ & $1,383,544,884,134$ & $1,383,544,884,135$ & 1 & 1 & 400.0 & 400.0 \\
\hline $0 \times 01$ & $1,383,544,884,133$ & $1,383,544,884,136$ & $1,383,544,884,138$ & 3 & 2 & $2,400.0$ & $1,400.0$ \\
\hline $0 \times 01$ & $1,383,544,884,133$ & $1,383,544,884,134$ & $1,383,544,884,136$ & 1 & 2 & 400.0 & $1,400.0$ \\
\hline $0 \times 01$ & $1,383,544,884,133$ & $1,383,544,884,134$ & $1,383,544,884,135$ & 1 & 1 & 400.0 & 400.0 \\
\hline $0 \times 01$ & $1,383,544,884,133$ & $1,383,544,884,134$ & $1,383,544,884,135$ & 1 & 1 & 400.0 & 400.0 \\
\hline $0 \times 01$ & $1,383,544,884,133$ & $1,383,544,884,134$ & $1,383,544,884,136$ & 1 & 2 & 400.0 & $1,400.0$ \\
\hline $0 \times 01$ & $1,383,544,884,133$ & $1,383,544,884,134$ & $1,383,544,884,135$ & 1 & 1 & 400.0 & 400.0 \\
\hline $0 \times 01$ & $1,383,544,884,133$ & $1,383,544,884,134$ & $1,383,544,884,136$ & 1 & 2 & 400.0 & $1,400.0$ \\
\hline $0 \times 01$ & $1,383,544,884,133$ & $1,383,544,884,135$ & $1,383,544,884,136$ & 2 & 1 & $1,400.0$ & 400.0 \\
\hline $0 \times 01$ & $1,383,544,884,133$ & $1,383,544,884,135$ & $1,383,544,884,137$ & 2 & 2 & $1,400.0$ & $1,400.0$ \\
\hline $0 \times 01$ & $1,383,544,884,133$ & $1,383,544,884,134$ & $1,383,544,884,136$ & 1 & 2 & 400.0 & $1,400.0$ \\
\hline $0 \times 01$ & $1,383,544,884,133$ & $1,383,544,884,135$ & $1,383,544,884,136$ & 2 & 1 & $1,400.0$ & 400.0 \\
\hline $0 \times 01$ & $1,383,544,884,133$ & $1,383,544,884,134$ & $1,383,544,884,135$ & 1 & 1 & 400.0 & 400.0 \\
\hline $0 \times 01$ & $1,383,544,884,134$ & $1,383,544,884,137$ & $1,383,544,884,138$ & 3 & 1 & $2,400.0$ & 400.0 \\
\hline $0 \times 01$ & $1,383,544,884,134$ & $1,383,544,884,135$ & $1,383,544,884,136$ & 1 & 1 & 400.0 & 400.0 \\
\hline $0 \times 01$ & $1,383,544,884,134$ & $1,383,544,884,135$ & $1,383,544,884,136$ & 1 & 1 & 400.0 & 400.0 \\
\hline $0 \times 01$ & $1,383,544,884,134$ & $1,383,544,884,137$ & $1,383,544,884,138$ & 3 & 1 & $2,400.0$ & 400.0 \\
\hline $0 \times 01$ & $1,383,544,884,134$ & $1,383,544,884,136$ & $1,383,544,884,137$ & 2 & 1 & $1,400.0$ & 400.0 \\
\hline $0 \times 01$ & $1,383,544,884,134$ & $1,383,544,884,137$ & $1,383,544,884,138$ & 3 & 1 & $2,400.0$ & 400.0 \\
\hline \multirow[t]{3}{*}{$0 \times 01$} & $1,383,544,884,134$ & $1,383,544,884,135$ & $1,383,544,884,136$ & 1 & 1 & 400.0 & 400.0 \\
\hline & & & & Average & & 1000 & 700 \\
\hline & & & & STD. & & 800.0 & 458.3 \\
\hline
\end{tabular}


Table 17. Processing Time of the Response Packet in the Sender-SIDE VIS

\begin{tabular}{|c|c|c|c|c|c|c|c|}
\hline \multirow[t]{2}{*}{$\begin{array}{l}\text { Packet } \\
\text { Type }\end{array}$} & \multicolumn{3}{|c|}{$\begin{array}{c}\text { TIMESTAMP IN VIS } \\
\text { (DOWNWARD THE STACK) }\end{array}$} & \multicolumn{2}{|c|}{$\begin{array}{l}\text { Elapsed Time } \\
\text { interval }(\Delta t) \text { in } \\
\text { milliseconds }\end{array}$} & \multicolumn{2}{|c|}{$\begin{array}{l}\text { Processing Time } \\
\text { in } \mu \text { sec } \\
=\Delta t-\text { Logging Delay } \\
\text { (0.6 milliseconds) }\end{array}$} \\
\hline & Application Layer & VNS Layer & Transport Layer & $\begin{array}{l}\text { VNS } \\
\text { Layer }\end{array}$ & $\begin{array}{l}\text { Transport } \\
\text { Layer }\end{array}$ & $\begin{array}{l}\text { VNS } \\
\text { Layer }\end{array}$ & $\begin{array}{l}\text { Transport } \\
\text { Layer }\end{array}$ \\
\hline $0 \times 02$ & $1,383,545,045,982$ & $1,383,545,045,983$ & $1,383,545,045,984$ & 1 & 1 & 400.0 & 400.0 \\
\hline $0 \times 02$ & $1,383,545,045,982$ & $1,383,545,045,983$ & $1,383,545,045,984$ & 1 & 1 & 400.0 & 400.0 \\
\hline $0 \times 02$ & $1,383,545,045,982$ & $1,383,545,045,983$ & $1,383,545,045,984$ & 1 & 1 & 400.0 & 400.0 \\
\hline $0 \times 02$ & $1,383,545,045,982$ & $1,383,545,045,985$ & $1,383,545,045,986$ & 3 & 1 & $2,400.0$ & 400.0 \\
\hline $0 \times 02$ & $1,383,545,045,982$ & $1,383,545,045,984$ & $1,383,545,045,986$ & 2 & 2 & $1,400.0$ & $1,400.0$ \\
\hline $0 \times 02$ & $1,383,545,045,982$ & $1,383,545,045,983$ & $1,383,545,045,984$ & 1 & 1 & 400.0 & 400.0 \\
\hline $0 \times 02$ & $1,383,545,045,982$ & $1,383,545,045,985$ & $1,383,545,045,987$ & 3 & 2 & $2,400.0$ & $1,400.0$ \\
\hline $0 \times 02$ & $1,383,545,045,982$ & $1,383,545,045,983$ & $1,383,545,045,984$ & 1 & 1 & 400.0 & 400.0 \\
\hline $0 \times 02$ & $1,383,545,045,982$ & $1,383,545,045,984$ & $1,383,545,045,986$ & 2 & 2 & $1,400.0$ & $1,400.0$ \\
\hline $0 \times 02$ & $1,383,545,045,983$ & $1,383,545,045,986$ & $1,383,545,045,987$ & 3 & 1 & $2,400.0$ & 400.0 \\
\hline $0 \times 02$ & $1,383,545,045,983$ & $1,383,545,045,986$ & $1,383,545,045,987$ & 3 & 1 & $2,400.0$ & 400.0 \\
\hline $0 \times 02$ & $1,383,545,045,983$ & $1,383,545,045,984$ & $1,383,545,045,985$ & 1 & 1 & 400.0 & 400.0 \\
\hline $0 \times 02$ & $1,383,545,045,983$ & $1,383,545,045,984$ & $1,383,545,045,985$ & 1 & 1 & 400.0 & 400.0 \\
\hline $0 \times 02$ & $1,383,545,045,983$ & $1,383,545,045,986$ & $1,383,545,045,987$ & 3 & 1 & $2,400.0$ & 400.0 \\
\hline $0 \times 02$ & $1,383,545,045,983$ & $1,383,545,045,985$ & $1,383,545,045,986$ & 2 & 1 & $1,400.0$ & 400.0 \\
\hline $0 \times 02$ & $1,383,545,045,983$ & $1,383,545,045,984$ & $1,383,545,045,985$ & 1 & 1 & 400.0 & 400.0 \\
\hline $0 \times 02$ & $1,383,545,045,983$ & $1,383,545,045,984$ & $1,383,545,045,986$ & 1 & 2 & 400.0 & $1,400.0$ \\
\hline $0 \times 02$ & $1,383,545,045,983$ & $1,383,545,045,985$ & $1,383,545,045,986$ & 2 & 1 & $1,400.0$ & 400.0 \\
\hline \multirow[t]{3}{*}{$0 \times 02$} & $1,383,545,045,983$ & $1,383,545,045,986$ & $1,383,545,045,987$ & 3 & 1 & $2,400.0$ & 400.0 \\
\hline & & & & \multicolumn{2}{|c|}{ Average } & 1242.1 & 610.5263 \\
\hline & & & & STD. & & 874.4 & 407.7 \\
\hline
\end{tabular}


Table-18. Processing time of the response packet in the receiver-side

\begin{tabular}{|c|c|c|c|c|c|c|c|}
\hline \multirow{2}{*}{$\begin{array}{c}\text { Packet } \\
\text { Type }\end{array}$} & \multicolumn{3}{|c|}{$\begin{array}{l}\text { TIMESTAMP IN THE VIS } \\
\text { (UPWARD THE STACK) }\end{array}$} & \multicolumn{2}{|c|}{$\begin{array}{c}\text { Elapsed Time } \\
\text { interval ( } \Delta \mathrm{t}) \\
\text { ( in milliseconds) }\end{array}$} & \multicolumn{2}{|c|}{$\begin{array}{c}\text { Processing Time } \\
\quad \text { (in } \mu \text { sec) } \\
=\Delta \text { t- Logging Delay } \\
\text { (0.6 milliseconds) }\end{array}$} \\
\hline & Transport Layer & OSL Layer & Application Layer & $\begin{array}{c}\text { Transport } \\
\text { Layer }\end{array}$ & $\begin{array}{c}\text { OSL } \\
\text { Layer }\end{array}$ & $\begin{array}{c}\text { Transport } \\
\text { Layer }\end{array}$ & $\begin{array}{c}\text { OSL } \\
\text { Layer }\end{array}$ \\
\hline $0 \times 02$ & $1,383,545,061,227$ & $1,383,545,061,228$ & $1,383,545,061,230$ & 1 & 2 & 400 & 1400 \\
\hline $0 \times 02$ & $1,383,545,061,227$ & $1,383,545,061,229$ & $1,383,545,061,230$ & 2 & 1 & 1400 & 400 \\
\hline $0 \times 02$ & $1,383,545,061,227$ & $1,383,545,061,228$ & $1,383,545,061,230$ & 1 & 2 & 400 & 1400 \\
\hline $0 \times 02$ & $1,383,545,061,227$ & $1,383,545,061,229$ & $1,383,545,061,230$ & 2 & 1 & 1400 & 400 \\
\hline $0 \times 02$ & $1,383,545,061,227$ & $1,383,545,061,228$ & $1,383,545,061,230$ & 1 & 2 & 400 & 1400 \\
\hline $0 \times 02$ & $1,383,545,061,227$ & $1,383,545,061,228$ & $1,383,545,061,229$ & 1 & 1 & 400 & 400 \\
\hline $0 \times 02$ & $1,383,545,061,227$ & $1,383,545,061,228$ & $1,383,545,061,229$ & 1 & 1 & 400 & 400 \\
\hline $0 \times 02$ & $1,383,545,061,227$ & $1,383,545,061,228$ & $1,383,545,061,229$ & 1 & 1 & 400 & 400 \\
\hline $0 \times 02$ & $1,383,545,061,227$ & $1,383,545,061,229$ & $1,383,545,061,230$ & 2 & 1 & 1400 & 400 \\
\hline $0 \times 02$ & $1,383,545,061,228$ & $1,383,545,061,229$ & $1,383,545,061,230$ & 1 & 1 & 400 & 400 \\
\hline $0 \times 02$ & $1,383,545,061,228$ & $1,383,545,061,230$ & $1,383,545,061,232$ & 2 & 2 & 1400 & 1400 \\
\hline $0 \times 02$ & $1,383,545,061,228$ & $1,383,545,061,230$ & $1,383,545,061,231$ & 2 & 1 & 1400 & 400 \\
\hline $0 \times 02$ & $1,383,545,061,228$ & $1,383,545,061,229$ & $1,383,545,061,231$ & 1 & 2 & 400 & 1400 \\
\hline $0 \times 02$ & $1,383,545,061,228$ & $1,383,545,061,229$ & $1,383,545,061,230$ & 1 & 1 & 400 & 400 \\
\hline $0 \times 02$ & $1,383,545,061,228$ & $1,383,545,061,229$ & $1,383,545,061,231$ & 1 & 2 & 400 & 1400 \\
\hline $0 \times 02$ & $1,383,545,061,228$ & $1,383,545,061,229$ & $1,383,545,061,231$ & 1 & 2 & 400 & 1400 \\
\hline $0 \times 02$ & $1,383,545,061,228$ & $1,383,545,061,229$ & $1,383,545,061,230$ & 1 & 1 & 400 & 400 \\
\hline $0 \times 02$ & $1,383,545,061,228$ & $1,383,545,061,230$ & $1,383,545,061,231$ & 2 & 1 & 1400 & 400 \\
\hline $0 \times 02$ & $1,383,545,061,228$ & $1,383,545,061,230$ & $1,383,545,061,232$ & 2 & 2 & 1400 & 1400 \\
\hline \multirow[t]{3}{*}{$0 \times 02$} & $1,383,545,061,228$ & $1,383,545,061,229$ & $1,383,545,061,231$ & 1 & 2 & 400 & 1400 \\
\hline & & & \multicolumn{3}{|c|}{ AVERAGE $=$} & 750 & 850 \\
\hline & & & \multicolumn{3}{|c|}{ STANDARD DEVIATION= } & 489.36 & 510.42 \\
\hline
\end{tabular}


Table-19:

Processing time of OSL acknowledgement packet in the sender-side VIS

\begin{tabular}{|c|c|c|c|c|c|c|c|}
\hline $\begin{array}{l}\text { Packet } \\
\text { Type }\end{array}$ & & $\begin{array}{l}\text { WNWARD THE STAC } \\
\text { TIMESTAMP IN VIS }\end{array}$ & & $\begin{array}{c}\text { Elaps } \\
\text { inter } \\
\text { in mil }\end{array}$ & $\begin{array}{l}d \text { Time } \\
\text { al }(\Delta t) \\
\text { econds }\end{array}$ & 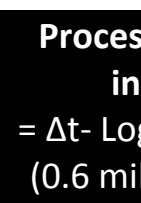 & $\begin{array}{l}\text { ng Time } \\
\text { sec } \\
\text { ing Delay } \\
\text { econds) }\end{array}$ \\
\hline $\begin{array}{c}3 \\
\text { MSB }\end{array}$ & Application Layer & OSL Layer & Transport Layer & $\begin{array}{c}\text { OSL } \\
\text { Layer }\end{array}$ & $\begin{array}{l}\text { Transport } \\
\text { Layer }\end{array}$ & $\begin{array}{c}\text { OSL } \\
\text { Layer }\end{array}$ & $\begin{array}{l}\text { Transport } \\
\text { Layer }\end{array}$ \\
\hline $0 \times 03$ & $1,383,545,534,153$ & $1,383,545,534,155$ & $1,383,545,534,156$ & 2 & 1 & $1,400.0$ & 400.0 \\
\hline $0 \times 03$ & $1,383,545,534,153$ & $1,383,545,534,154$ & $1,383,545,534,155$ & 1 & 1 & 400.0 & 400.0 \\
\hline $0 \times 03$ & $1,383,545,534,153$ & $1,383,545,534,154$ & $1,383,545,534,156$ & 1 & 2 & 400.0 & $1,400.0$ \\
\hline $0 \times 03$ & $1,383,545,534,153$ & $1,383,545,534,154$ & $1,383,545,534,156$ & 1 & 2 & 400.0 & $1,400.0$ \\
\hline $0 \times 03$ & $1,383,545,534,154$ & $1,383,545,534,155$ & $1,383,545,534,157$ & 1 & 2 & 400.0 & $1,400.0$ \\
\hline $0 \times 03$ & $1,383,545,534,154$ & $1,383,545,534,155$ & $1,383,545,534,157$ & 1 & 2 & 400.0 & $1,400.0$ \\
\hline $0 \times 03$ & $1,383,545,534,154$ & $1,383,545,534,157$ & $1,383,545,534,158$ & 3 & 1 & $2,400.0$ & 400.0 \\
\hline $0 \times 03$ & $1,383,545,534,154$ & $1,383,545,534,155$ & $1,383,545,534,156$ & 1 & 1 & 400.0 & 400.0 \\
\hline $0 \times 03$ & $1,383,545,534,154$ & $1,383,545,534,156$ & $1,383,545,534,157$ & 2 & 1 & $1,400.0$ & 400.0 \\
\hline $0 \times 03$ & $1,383,545,534,154$ & $1,383,545,534,156$ & $1,383,545,534,157$ & 2 & 1 & $1,400.0$ & 400.0 \\
\hline $0 \times 03$ & $1,383,545,534,154$ & $1,383,545,534,156$ & $1,383,545,534,158$ & 2 & 2 & $1,400.0$ & $1,400.0$ \\
\hline $\begin{array}{r}10 \times 0 \\
3\end{array}$ & $1,383,545,534,154$ & $1,383,545,534,155$ & $1,383,545,534,156$ & 1 & 1 & 400.0 & 400.0 \\
\hline $0 \times 03$ & $1,383,545,534,154$ & 1,383,545,534,155 & $1,383,545,534,156$ & 1 & 1 & 400.0 & 400.0 \\
\hline $0 \times 03$ & $1,383,545,534,154$ & $1,383,545,534,155$ & $1,383,545,534,157$ & 1 & 2 & 400.0 & $1,400.0$ \\
\hline $0 \times 03$ & $1,383,545,534,154$ & $1,383,545,534,155$ & $1,383,545,534,157$ & 1 & 2 & 400.0 & $1,400.0$ \\
\hline $0 \times 03$ & $1,383,545,534,154$ & $1,383,545,534,157$ & $1,383,545,534,158$ & 3 & 1 & $2,400.0$ & 400.0 \\
\hline $0 \times 03$ & $1,383,545,534,154$ & $1,383,545,534,155$ & $1,383,545,534,156$ & 1 & 1 & 400.0 & 400.0 \\
\hline $0 \times 03$ & $1,383,545,534,154$ & $1,383,545,534,155$ & $1,383,545,534,157$ & 1 & 2 & 400.0 & $1,400.0$ \\
\hline $0 \times 03$ & $1,383,545,534,154$ & $1,383,545,534,155$ & $1,383,545,534,157$ & 1 & 2 & 400.0 & $1,400.0$ \\
\hline \multirow[t]{3}{*}{$0 \times 03$} & $1,383,545,534,154$ & $1,383,545,534,156$ & $1,383,545,534,157$ & 2 & 1 & 1400.0 & 400.0 \\
\hline & & & & \multicolumn{2}{|l|}{ Average } & 821.05 & 873.6842 \\
\hline & & & & STD. & & 674.00 & 499.3000 \\
\hline
\end{tabular}


TABLE 20:

Processing time of OSL acknowledgement packet in the receiver-side VIS

\begin{tabular}{|c|c|c|c|c|c|c|c|}
\hline $\begin{array}{l}\text { Packet } \\
\text { Type }\end{array}$ & & $\begin{array}{l}\text { UPWARD THE STACK } \\
\text { TIMESTAMP IN VIS }\end{array}$ & & $\begin{array}{l}\text { Elapsed } \\
\text { interval ( } \\
\text { millisecc }\end{array}$ & $\begin{array}{l}\text { ime } \\
\text { t) in } \\
\text { nds }\end{array}$ & $\begin{array}{r}\text { Processi } \\
\text { in } \mu \\
=\Delta \mathrm{t}-\text { Logg } \\
(0.6 \text { millis }\end{array}$ & $\begin{array}{l}\text { Time } \\
\text { c } \\
\text { Delay } \\
\text { onds) }\end{array}$ \\
\hline 3 MSB & Transport Layer & OSL Layer & Application Layer & $\begin{array}{l}\text { Transport } \\
\text { Layer }\end{array}$ & $\begin{array}{l}\text { OSL } \\
\text { Layer }\end{array}$ & $\begin{array}{l}\text { Transport } \\
\text { Layer }\end{array}$ & $\begin{array}{c}\text { OSL } \\
\text { Layer }\end{array}$ \\
\hline $0 \times 03$ & $1,383,545,579,407$ & $1,383,545,579,409$ & $1,383,545,579,410$ & 2 & 1 & $1,400.0$ & 400.0 \\
\hline $0 \times 03$ & $1,383,545,579,407$ & $1,383,545,579,409$ & $1,383,545,579,410$ & 2 & 1 & $1,400.0$ & 400.0 \\
\hline $0 \times 03$ & $1,383,545,579,407$ & $1,383,545,579,408$ & $1,383,545,579,409$ & 1 & 1 & 400.0 & 400.0 \\
\hline $0 \times 03$ & $1,383,545,579,407$ & $1,383,545,579,408$ & $1,383,545,579,409$ & 1 & 1 & 400.0 & 400.0 \\
\hline $0 \times 03$ & $1,383,545,579,407$ & $1,383,545,579,408$ & $1,383,545,579,409$ & 1 & 1 & 400.0 & 400.0 \\
\hline $0 \times 03$ & $1,383,545,579,407$ & $1,383,545,579,408$ & $1,383,545,579,409$ & 1 & 1 & 400.0 & 400.0 \\
\hline $0 \times 03$ & $1,383,545,579,407$ & $1,383,545,579,408$ & $1,383,545,579,409$ & 1 & 1 & 400.0 & 400.0 \\
\hline $0 \times 03$ & $1,383,545,579,407$ & $1,383,545,579,409$ & $1,383,545,579,410$ & 2 & 1 & $1,400.0$ & 400.0 \\
\hline $0 \times 03$ & $1,383,545,579,407$ & $1,383,545,579,408$ & $1,383,545,579,409$ & 1 & 1 & 400.0 & 400.0 \\
\hline $0 \times 03$ & $1,383,545,579,407$ & $1,383,545,579,409$ & $1,383,545,579,410$ & 2 & 1 & $1,400.0$ & 400.0 \\
\hline $0 \times 03$ & $1,383,545,579,407$ & $1,383,545,579,408$ & $1,383,545,579,409$ & 1 & 1 & 400.0 & 400.0 \\
\hline $0 \times 03$ & $1,383,545,579,407$ & $1,383,545,579,408$ & $1,383,545,579,409$ & 1 & 1 & 400.0 & 400.0 \\
\hline $0 \times 03$ & $1,383,545,579,408$ & $1,383,545,579,409$ & $1,383,545,579,410$ & 1 & 1 & 400.0 & 400.0 \\
\hline $0 \times 03$ & $1,383,545,579,408$ & $1,383,545,579,410$ & $1,383,545,579,411$ & 2 & 1 & $1,400.0$ & 400.0 \\
\hline $0 \times 03$ & $1,383,545,579,408$ & $1,383,545,579,409$ & $1,383,545,579,410$ & 1 & 1 & 400.0 & 400.0 \\
\hline $0 \times 03$ & $1,383,545,579,408$ & $1,383,545,579,409$ & $1,383,545,579,410$ & 1 & 1 & 400.0 & 400.0 \\
\hline $0 \times 03$ & $1,383,545,579,408$ & $1,383,545,579,410$ & $1,383,545,579,411$ & 2 & 1 & $1,400.0$ & 400.0 \\
\hline $0 \times 03$ & $1,383,545,579,408$ & $1,383,545,579,409$ & $1,383,545,579,410$ & 1 & 1 & 400.0 & 400.0 \\
\hline $0 \times 03$ & $1,383,545,579,408$ & $1,383,545,579,409$ & $1,383,545,579,410$ & 1 & 1 & 400.0 & 400.0 \\
\hline \multirow[t]{3}{*}{$0 \times 03$} & $1,383,545,579,408$ & $1,383,545,579,410$ & $1,383,545,579,411$ & 2 & 1 & $1,400.0$ & 400.0 \\
\hline & & & & Average & & 750.0 & 400.0 \\
\hline & & & & STD. & & 477.0 & 0.0 \\
\hline
\end{tabular}

TABLE 22: APPLICATION AUTHENTICATION DATABASE AT NAP

\section{APPLICATION AUTHENTICATION DATABASE AT NAP}

\begin{tabular}{|l|l|}
\hline Application_UUID & String \\
\hline Application_Name & String \\
\hline Vendor_Name & String \\
\hline Application_Version & Number \\
\hline Application_specific_Public_Key & Big Integer \\
\hline
\end{tabular}




\section{TABLE 23: A SAMPLE SESSION REQUEST PACKET}

$1|0| 0|1| 66|39|-70|-11|-31|-1|-40|-1|-32|0| 16|74| 70|73| 70|0| 1|2| 0|0| 1|0| 1|0| 0|-1|-$

$37|0| 67|0| 8|6| 6|7| 6|5| 8|7| 7|7| 9|9| 8|10| 12|20| 13|12| 11|11| 12|25| 18|19| 15|20| 29|26| 31|30| 29|26| 28|28| 32|36| 46 \mid$ $39|32| 34|44| 35|28| 28|40| 55|41| 44|48| 49|52| 52|52| 31|39| 57|61| 56|50| 60|46| 51|52| 50|-1|-$

$37|0| 67|1| 9|9| 9|12| 11|12| 24|13| 13|24| 50|33| 28|33| 50|50| 50|50| 50|50| 50|50| 50|50| 50|50| 50|50| 50|50| 50|50| 50 \mid 50$ $150|50| 50|50| 50|50| 50|50| 50|50| 50|50| 50|50| 50|50| 50|50| 50|50| 50|50| 50|50| 50|50| 50|50| 50|50|-1 \mid-$

$64|0| 17|8| 0|37| 0|37| 3|1| 34|0| 2|17| 1|3| 17|1|-1 \mid-$

$60|0| 31|0| 0|1| 5|1| 1|1| 1|1| 1|0| 0|0| 0|0| 0|0| 0|1| 2|3| 4|5| 6|7| 8|9| 10|11|-1|-60| 0 \mid-$

$75|16| 0|2| 1|3| 3|2| 4|3| 5|5| 4|4| 0|0| 1|125| 1|2| 3|0| 4|17| 5|18| 33|49| 65|6| 19|81| 97|7| 34|113| 20|50|-127|-111|-$ $95|8| 35|66|-79|-63| 21|82|-47|-16| 36|51| 98|114|-$

$126|9| 10|22| 23|24| 25|26| 37|38| 39|40| 41|42| 52|53| 54|55| 56|57| 58|67| 68|69| 70|71| 72|73| 74|83| 84|85| 86|87| 88|89|$ $90|99| 100|101| 102|103| 104|105| 106|115| 116|117| 118|119| 120|121| 122|-125|-124|-123|-122|-121|-120|-119|-118 \mid-$ 110|-109|-108|-107|-106|-105|-104|-103|-102|-94|-93|-92|-91|-90|-89|-88|-87|-86|-78|-77|-76|-75|-74|-73|-72|-71|-70|$62|-61|-60|-59|-58|-57|-56|-55|-54|-46|-45|-44|-43|-42|-41|-40|-39|-38|-31|-30|-29|-28|-27|-26|-25|-24|-23|-22|-15 \mid-$ $14|-13|-12|-11|-10|-9|-8|-7|-6|-1|-60|0| 31|1| 0|3| 1|1| 1|1| 1|1| 1|1| 1|0| 0|0| 0|0| 0|1| 2|3| 4|5| 6|7| 8|9| 10|11|-1|-60| 0 \mid-$ $75|17| 0|2| 1|2| 4|4| 3|4| 7|5| 4|4| 0|1| 2|119| 0|1| 2|3| 17|4| 5|33| 49|6| 18|65| 81|7| 97|113| 19|34| 50|-127| 8|20| 66|-111|-$ $95|-79|-63|9| 35|51| 82|-16| 21|98| 114|-47| 10|22| 36|52|-31|37|-$

$15|23| 24|25| 26|38| 39|40| 41|42| 53|54| 55|56| 57|58| 67|68| 69|70| 71|72| 73|74| 83|84| 85|86| 87|88| 89|90| 99|100| 101 \mid 1$ $02|103| 104|105| 106|115| 116|117| 118|119| 120|121| 122|-126|-125|-124|-123|-122|-121|-120|-119|-118|-110|-109|-108 \mid-$ 107|-106|-105|-104|-103|-102|-94|-93|-92|-91|-90|-89|-88|-87|-86|-78|-77|-76|-75|-74|-73|-72|-71|-70|-62|-61|-60|-59|$58|-57|-56|-55|-54|-46|-45|-44|-43|-42|-41|-40|-39|-38|-30|-29|-28|-27|-26|-25|-24|-23|-22|-14|-13|-12|-11|-10|-9|-8|-$ $7|-6|-1|-38| 0|12| 3|1| 0|2| 17|3| 17|0| 63|0|-11|-113| 22|-8|-76|-8| 92|-62| 76|22|-51|11| 65|36|-14|-51| 115|60|-111 \mid-$ $84|106|-113|20| 96|97| 34|-111|-104|-106|-103|123| 113|-118|-58|127|-118|16| 90|90| 67|115| 125|-89| 102|57| 37|113|-$ $70|-54| 115|54| 98|91| 68|-71| 14|-86|-56|-114| 114|36| 80|114|-95|87|-110|-52|-68|103| 75|-58|-38|5|-10|-80| 108|-27|-$ $79|-74| 75|-110|-118|-16| 75|28|-109|-60|-118|82| 71|-120|-110|86| 88|37| 86|0|-58|27|-79|27| 120|-36| 78|43|-121 \mid-$ $113|85|-78|-45| 70|-97| 113|44|-82|-6| 13|-44|-16|-50| 117|31|-74|121| 112|111|-115|32|-108|-88|-115|45| 85|73|-$ $116|90| 44|106|-96|2|-59|-39| 70|27| 120|-113|-33|-64|-31|48|-43|-88| 69|-72| 115|75| 91|-39|-21|-27|-89|123| 109|-34|-$ $37|110|-52|-91| 38|-98|-26|-4|-97|21| 36|125| 103|-5| 34|-37| 65|-51|-14|75| 52|115|-57|45|-14|57|-113|102|-46|48|-$ $80|9| 93|-40|-122|25| 10|-65| 41|12| 50|66| 59|45|-69|-97|-120|-78| 69|-86| 91|-39| 13|58|-38|-35|-18|-89|-114|-38|-$ $38|61| 66|-26| 104|-90| 121|26| 40|100| 42|-56|-112|72| 16|-113| 61|20|-27|-70|-26|-72|-85|-115| 23|81| 105|-84| 108|-37|-$ $62|-9|-70|-115|-31|-74|-35|-66| 9|101|-114|-49|-52|9| 20|-118| 37|-114| 88|34|-113|99| 52|72| 10|111| 37|87| 41|-57|-$ $105|18|-84|-112| 92|91| 57|-45| 46|112|-22|-9| 54|102|-5|79|-72|-1| 0|64| 88|100|-106|-34|-35|67|-7|123|-95|127|-$ $77|48| 16|-63|-72|18|-88|-84| 36|0|-97|45| 119|-10|-68|-65| 8|-46| 106|29| 31|-38|-7|-89|-69|-45| 71|-93|-24|-101|-13|39|-$ $98|71|-81|-24|-70|-113|-10|-58|-125|-89| 106|126| 87|-109|-10|-53| 104|-18| 60|-67|-37|-74| 111|80|-40|-50| 6|113|-98 \mid-$ $72|-94|-115|22|-51|52|-19|7| 78|-79|-114|57|-93|-114|-38|-38| 56|85| 39|42| 100|80|-86|0| 12|87|-27|45|-57|56|-$ $29|61| 40|-81|-105|-85|-53|-49| 46|77|-81|-95|-78|-40|-26|62| 32|-63|-89|-35| 37|-110| 77|19|-1|0| 105|-37| 44|-105|-$ $106|50|-86|-82| 3|3| 28|91| 73|-5|-8|45| 60|103| 17|-2|-16|-108| 5|14|-16|-128|-14|-80| 105|-6| 69|-107|-102|11|-$ $123|75| 49|30|-95|36|-33|100|-65|-72| 18|19| 103|106|-114|-110|-89|-103| 20|89|-100|-84| 83|50|-7|70| 73|0| 11|-76|-$ 79|9|34|86|-1|0|-60|-106|-71|47|111|29|-67|-116|-41|-8|-79|-72|-111|-84|-19|-19|-95|-106|73|-15|61|-86|-19|-3|$28|82|-31|70|-3|-28| 5|-28|-96|39|-96|-57| 15|115| 98|-77| 38|-103| 105|62|-103|48|-74|-77|-66|26|-115|-59|-85|8| 45 \mid-$ $29|-118| 53|-126|-54|73| 22|120|-110|36| 89|27|-9|-51| 24|98| 16|40| 98|92|-124|12| 71|-45| 101|-76|-36|-80|-$ $80|78| 86|78|-3|117|-46|-1| 0|-81|-33|-47|-34|-24|-58|111|-34|52|-96|-45| 82|77| 66|93| 83|82|-80|-71| 75|-37| 91|56| 35 \mid-$ $77|-114|-56|-49| 11|36|-13|-53|-28|-7|-124|-53| 36|83| 48|-110| 77|-60| 6|100| 31|-21|-117|114|-30|89| 121 \mid-$ $3|50| 13|43| 82|-97| 72|72|-30|-41|-11|45| 62|-17| 76|-73|-116|-23| 15|-87|-88|121|-40|92|-52|-97| 54|93| 11|36| 65|25|-$ $108|34|-128|48| 25|-116| 99|113| 47|-70|-16|-108| 3|80|-80|-74|-121|100|-9|18| 105|86|-13|91| 91|-117|-117|121| 60 \mid-$ $120|76|-79|5| 36|-55| 31|-109| 51|52|-46|48| 10|-122| 32|-22|-121|44|-51|51| 102|117|-45|-76|-3|58| 93|22| 121|-20| 52 \mid-$ $101|-117| 43|40| 36|23| 18|-40|-38|45|-60|87|-30|56| 85|-33| 19|61|-78|-57|-100|91|-54|-36| 59|-66|-9|100|-36|-128|-$ $106|79| 78|45| 40|-66| 89|-73| 125|-73|-47|36|-4|-17|-85|-39|-23|-82|-73|-22| 65|-20|-2|24| 93|-98| 19|-47|-105|-53|-$ $122|44| 88|-64| 60|-72| 36|-13| 35|95|-35|-81| 10|-37|-101|114|-114|-57| 113|-56|-18|122|-47|86|-76|-79| 40|-46| 108|-60|-$ $10|-17| 111|55|-112|-98| 100|50| 78|102| 104|-37| 104|-54|-103|15| 46|65|-29|119| 126|-76| 87|-61| 86|124|-43|36|-4|-39|-$ $46|-74| 25|-88|-24|-70| 86|-79|-27|-1| 0|105|-23|-106| 87|-66| 86|124|-65|-76|-64|-78| 108|-50| 51|-115|-64|-29| 56|31|-$ $112|-88|-19|60| 61|-94|-40|60| 47|103|-93|-23|-10|-17| 3|59|-60|-48|-37|34| 24|-39|-128|86| 43|-127|-63|32| 0|72|-$ $22|0| 20|81| 66|-85| 81|71|-107|73|-37|-75|-62|-56|-111|116| 93|41| 44|35|-80|93| 50|-56| 89|-57|-69|101|-72|-127| 124 \mid-$ $75|-36| 24|54| 23|24| 25|14|-32|-6|-122|62|-90|-98| 116|-67| 60|-49| 60|-26|-58|-37|-50|-99|-93|121|-92|-14| 87|116|-$ $115|25| 6|50|-57|25| 37|72| 24|39|-90|56|-94|-118| 94|-46| 125|-33|-11|-81|-26|22| 45|-47| 69|21| 3|63|-1|-39|$ 


\section{TABLE 24: A SAMPLE CHALLENGE PACKET}

$33|0| 0|1| 66|39|-70|-10| 0|0| 0|5| 78|-1|-40|-1|-32|0| 16|74| 70|73| 70|0| 1|2| 0|0| 1|0| 1|0| 0|-1|-$

$37|0| 67|0| 8|6| 6|7| 6|5| 8|7| 7|7| 9|9| 8|10| 12|20| 13|12| 11|11| 12|25| 18|19| 15|20| 29|26| 31|30| 29|26| 28|28| 3$ $2|36| 46|39| 32|34| 44|35| 28|28| 40|55| 41|44| 48|49| 52|52| 52|31| 39|57| 61|56| 50|60| 46|51| 52|50|-1 \mid-$

$37|0| 67|1| 9|9| 9|12| 11|12| 24|13| 13|24| 50|33| 28|33| 50|50| 50|50| 50|50| 50|50| 50|50| 50|50| 50|50| 50|50| 50$ $|50| 50|50| 50|50| 50|50| 50|50| 50|50| 50|50| 50|50| 50|50| 50|50| 50|50| 50|50| 50|50| 50|50| 50|50| 50|50| 50 \mid 50$ $|-1|-64|0| 17|8| 0|33| 0|33| 3|1| 34|0| 2|17| 1|3| 17|1|-1 \mid-$

$60|0| 31|0| 0|1| 5|1| 1|1| 1|1| 1|0| 0|0| 0|0| 0|0| 0|1| 2|3| 4|5| 6|7| 8|9| 10|11|-1|-60| 0 \mid-$

$75|16| 0|2| 1|3| 3|2| 4|3| 5|5| 4|4| 0|0| 1|125| 1|2| 3|0| 4|17| 5|18| 33|49| 65|6| 19|81| 97|7| 34|113| 20|50|-127 \mid-$ $111|-95| 8|35| 66|-79|-63|21| 82|-47|-16|36| 51|98| 114 \mid-$

$126|9| 10|22| 23|24| 25|26| 37|38| 39|40| 41|42| 52|53| 54|55| 56|57| 58|67| 68|69| 70|71| 72|73| 74|83| 84|85| 86 \mid$ $87|88| 89|90| 99|100| 101|102| 103|104| 105|106| 115|116| 117|118| 119|120| 121|122|-125|-124|-123|-122|-121 \mid-$ 120|-119|-118|-110|-109|-108|-107|-106|-105|-104|-103|-102|-94|-93|-92|-91|-90|-89|-88|-87|-86|-78|-77|-76|$75|-74|-73|-72|-71|-70|-62|-61|-60|-59|-58|-57|-56|-55|-54|-46|-45|-44|-43|-42|-41|-40|-39|-38|-31|-30|-29 \mid-$ $28|-27|-26|-25|-24|-23|-22|-15|-14|-13|-12|-11|-10|-9|-8|-7|-6|-1|-$

$60|0| 31|1| 0|3| 1|1| 1|1| 1|1| 1|1| 1|0| 0|0| 0|0| 0|1| 2|3| 4|5| 6|7| 8|9| 10|11|-1|-60| 0 \mid-$

75|17|0|2|1|2|4|4|3|4|7|5|4|4|0|1|2|119|0|1|2|3|17|4|5|33|49|6|18|65|81|7|97|113|19|34|50|$127|8| 20|66|-111|-95|-79|-63| 9|35| 51|82|-16|21| 98|114|-47|10| 22|36| 52|-31| 37 \mid-$

$15|23| 24|25| 26|38| 39|40| 41|42| 53|54| 55|56| 57|58| 67|68| 69|70| 71|72| 73|74| 83|84| 85|86| 87|88| 89|90| 99 \mid$ $100|101| 102|103| 104|105| 106|115| 116|117| 118|119| 120|121| 122|-126|-125|-124|-123|-122|-121|-120|-119 \mid-$ 118|-110|-109|-108|-107|-106|-105|-104|-103|-102|-94|-93|-92|-91|-90|-89|-88|-87|-86|-78|-77|-76|-75|-74|$73|-72|-71|-70|-62|-61|-60|-59|-58|-57|-56|-55|-54|-46|-45|-44|-43|-42|-41|-40|-39|-38|-30|-29|-28|-27|-26 \mid-$ $25|-24|-23|-22|-14|-13|-12|-11|-10|-9|-8|-7|-6|-1|-38|0| 12|3| 1|0| 2|17| 3|17| 0|63| 0|-11|-113|22|-8|-76|-$ $8|92|-62|76| 22|-51| 11|65| 36|-14|-51|115| 60|-111|-84|106|-113|20| 96|97| 34|-111|-104|-106|-103|123| 113 \mid-$ $118|-61|-109|-30|-110|-37|-117|4|-105|75| 73|-89|-65|-68|-114|-42|-38|43| 75|-110|-34|104| 116|-73|-$ $111|92| 25|35| 64|6|-53|-127|-61|109| 59|-126|-114|-123|-103|39|-8|-117| 108|-13|-51|96| 98 \mid-$

$123|38| 127|34| 88|-116| 79|113| 2|-119| 119|-53| 110|-85| 31|-105| 44|50|-122|45| 39|-107|-122|-62|-86 \mid-$ $112|55| 48|-56|-82|42|-17|86|-45|78|-120|69|-115|-66|-89|115|-89|-22|-105|63| 101|-126|-14|88|-68|-107|-$ $70|2| 91|88|-102|5|-14|32| 15|26|-76|80| 56|1| 6|10|-82|48|-17|-108|-113|-24|-16|24| 26|21| 104|83|-108|-87|-$ $13|54|-38|122|-7|-23|-8|107|-46|-23| 105|-43|-104|-54| 77|55|-87|-34| 88|124| 67|-117| 84|-48| 77|-27|-90|-100|-$ $30|-4| 79|21|-65|-39|-90|-108| 121|69|-98|100|-121|120|-103|3|-87|-113| 123|-80| 86|-57|-49|-27|-66|7|-$ $54|113| 39|-123| 60|116| 60|81| 126|-112|-61|5|-109|91| 73|20|-52|-77|-37|92|-54|-8| 120|-116| 33|-108|-84 \mid-$ $112|-58| 122|78|-89|35| 61|13| 113|-70| 69|-92|-106|-66| 27|-76|-97|85|-118|-10|-46|-14|-9|55| 127|99|-114 \mid-$ $35|34|-98|-48| 91|-7| 30|100|-66|100|-53|-27|-94|110|-73|-127|-124|109|-27|34|-85|-107| 27|-10|-58|6|-25 \mid-$ $61|-53| 37|-2|-45|-106|-31|32|-14|-123|-84|82|-60|-55| 19|64| 34|70|-111|-45| 32|-84| 86|-15| 17|46| 32|5|-107 \mid-$ $16|-56|-90|48| 70|88|-124|88|-116|30| 22|-99| 42|-110| 81|-39|-69|106|-12|-23|-13|-76|-76|-65|-82|-6| 2|-108|-$ $101|71|-93|-47| 69|21|-13|-90|-57|35|-29|-121| 86|-127| 109|98|-69|120| 47|-25|-77|-71| 88|22| 45|44|-34|52|-$ $125|8| 10|-66| 35|-109| 108|57| 41|-68| 109|-53| 124|-72| 35|4| 30|30| 61|46| 34|13|-60|-41| 41|109| 28|-117| 37 \mid-$ $75|-51|-3|-43|-104|17|-23|119|-91|33|-111|102| 30|106| 69|42| 51|110|-111|68|-84|-50|-52|68| 5|-103|-114|0|-$ $19|124| 117|-31| 75|-65| 20|44| 48|-61| 28|50| 91|27| 105|109|-25|87|-69|54|-18|55| 75|4|-118|85|-124|82| 14 \mid-$ 80|96|-126|59|-42|53|-65|-126|-4|81|-89|-61|3|-23|-46|105|49|73|108|-63|-95|-126|-26|-30|105|83|41|21|$84|49|-79|116| 88|-50|-19|-80| 75|-109|-73|24|-112|-90| 8|118|-57|-47| 96|107| 82|-89|-121|-113|-66|-108|-75 \mid-$ $34|-33| 47|63|-66|-23| 122|59| 24|-55| 54|-10| 57|-8|-83|109|-75|29| 70|-21| 65|-79|-47|33|-72|17| 92 \mid-$ $104|94| 105|110|-26|40|-94|8|-19|-93|-14|-112| 4|109|-34|92|-78|68| 11|60| 91|29| 32|-116|-72|114| 11|47| 65 \mid-$ $16|-2| 88|-114|-71|10|-99|1| 44|33| 109|41| 31|75|-98|53| 0|121| 12|33|-110|88|-77|-99|-50|21|-91|-117|-$ $26|96|-59|-97|-50|108|-115|-37| 22|125| 75|-31|-60|-6|-52|-19|-3|-85| 113|-89|-49|106|-9|-119| 115|36| 22 \mid-$ $74|81|-37|43|-122|35|-51|1|-74|60|-86|-57| 98|49| 113|33| 47|-54| 16|-125| 13|91|-98|28|-47|53| 61|42|-6|52|-$ $71|-39|-10|11| 125|62| 11|59| 85|75|-7|31| 96|69| 92|-18|-113|98|-93|49| 109|-33|-68|-32|-19|84| 1|87|-26 \mid-$ $51|98| 113|-108| 103|-121| 113|-116|-82|-19|-35|-2| 23|107| 94|-22|-42|-75|-41|-95| 24|-69|-$

$99|61| 20|81| 95|54| 108|20| 81|69| 0|20| 81|69| 0|20| 81|69| 0|127|-1|-39| 46|106| 40|44|-25|52|-7|115| 41|63|-$ $3|91|-83|-51|-105|-84| 76|-64| 50|110|-32|-14| 74|-100|-110|3|-97|-70|-85|121|-116|-34| 77|-11|-106|-56| 34|1|-$ $65|106| 1|-19|-92|18| 108|-49| 21|97| 121|27| 41|112| 110|115| 62|-38| 78|-55| 55|-28|-11|-48| 113|-101| 24|52|-$ $2|-26| 111|-74| 101|69| 8|89|-94|67| 98|53| 40|-104| 68|-30| 87|66|-46|120| 29|-123|-89|-26|-125|6| 49|-22|-$ $102|118| 70|57| 34|-70|-67|16|-85|17|-98|-121| 42|-116|-67|-63|-14|44| 113|100| 30|-122| 46|-66|-99|85| 12|46|-$ $22|-18|-2|-52| 44|49|$ 
Table-25: A sample RESPONSE packet

$65|0| 0|1| 66|39|-70|-9| 103|0| 0|4|-45|77| 124|-29|-102|-73| 37|76|-42|9|-31 \mid-$

$60|31| 81|21| 37|-94|-94|75|-44|1|-25|38|-96|105|-49|-59|-67|-11|-13|-65|-$

$10|103| 46|45|-13|-15|-75|36| 96|119| 21|25| 36|-33| 108|29| 15|-121| 42|115| 93|-19|-56 \mid-$ $79|-7| 38|-43|-4|82| 64|14| 55|-65| 40|-36| 97|-92|-115|98|-85|54| 120|-77| 111|-120|-26 \mid-$ $35|-128|-20|-104|-24|88|-7|53|-15|-14|-31|16| 33|114| 1|74| 68|81|-24|-2|-27|-100| 44 \mid-$ $71|-87| 6|-97| 10|2|-23|63|-52|99|-58|-127|-85|63| 112|81|-97|107|-37|-69| 78|-32|-27 \mid-$ $69|-120|-50|-14| 33|93|$

Table-26: A sample OSL Acknowledgement packet

$97|0| 0|1| 66|39|-70|-9|-90|0| 3|-95| 66|0| 69|-82| 0|-70| 107 \mid-$

$27|31| 1|103| 82|97| 46|113|-95|15| 96|119|-17|65| 15|-80| 59|-62|-69|101|-44|72|-$ $112|56| 88|111|-44|-50|-122|24| 54|-47| 30|-92|-59|28|-65|70| 32|-99|-113|83|-66 \mid-$ $16|72| 60|-76| 102|23|-83|-101|-48|55|-39|-54| 127|-70| 0|-98| 25|11|-$ $105|36| 28|13|-107|101| 115|126| 21|95|-96|-40|-114|-118| 89|-107|-38|60|-111 \mid-$ $23|-105|-56|25| 69|93| 126|-34|-124|-35| 32|9|-14|8| 3|-101| 17|81|-48|-1| 62 \mid-$ $62|56|-121|100|-5|-41| 63|6|-71|-31|-30|93| 100|-8|-1|126| 61|-96| 95|-7|-18|92|-$ $77|0|-71 \mid$

Table-27: A sample Data Communication packet

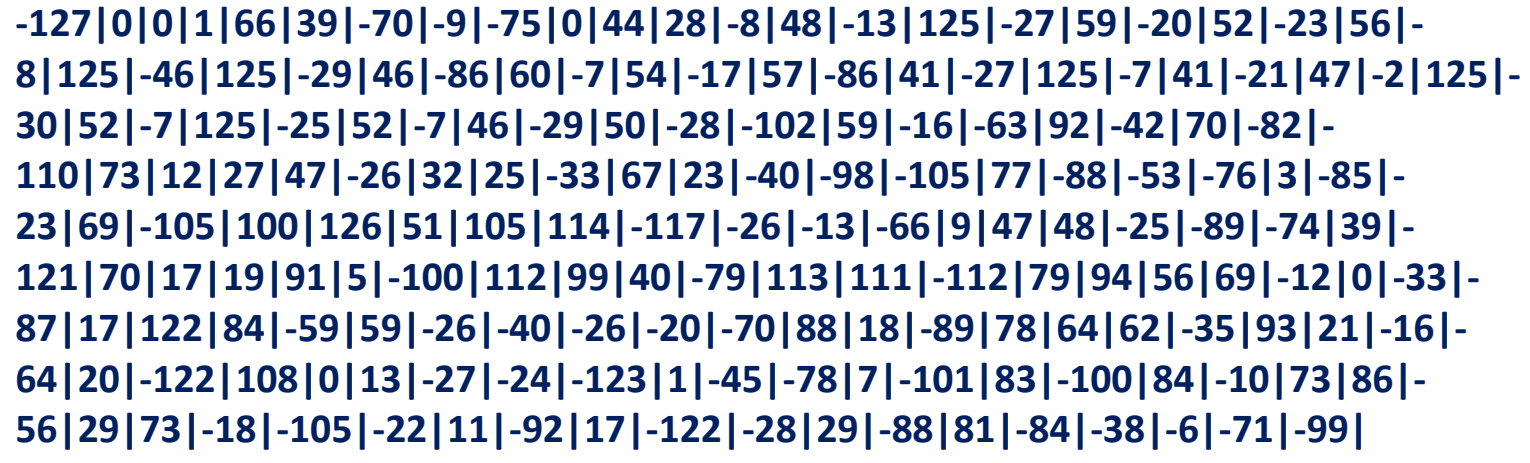


TABLE 28: KEYS OF THE SERVER

\section{PRIVATE KEY OF THE SERVER}

93632166035672942999869443652446366821128962009188675105500097928710583288

72873411317162971107390855259434642629576847033880663274773999054952551786 52628551505613731052702203877726203841202858511642288445521677453012215970 04639006359294453490292923967036744914550406950360220408454895269365879988 318545257739

29793936104916666208695506018403596955732233299351826153929826543865762911 07540810833698774729901107703743687342984811145529202617332758232631651051 40941937267729047202267629159225221003739222323370640793147440581659632473 64592709460504451856531560825720878594550313434435661149593117867720601743 906685260225

\section{PUBLIC KEY OF THE SERVER}

93632166035672942999869443652446366821128962009188675105500097928710583288 72873411317162971107390855259434642629576847033880663274773999054952551786 52628551505613731052702203877726203841202858511642288445521677453012215970 04639006359294453490292923967036744914550406950360220408454895269365879988 318545257739

65537

\section{References}

[1] J. F. Zandbelt, R. J. Hulsebosch, M. S. Bargh and R. Arends, "Trusted Directory Services for Secure Internet Connectivity: Transport Layer Security using DNSSEC”, Electronic Notes in Theoretical Computer Science, vol. 197, Issue 2, (2008) February 22, pp. 91-103, ISSN 1571-0661, http://dx.doi.org/10.1016/j.entcs.2007.12.019.

[2] H. T. Panduranga and S. K. N. Kumar, "A Novel Image Encryption Technique using Multi-Wave Based Carrier Image”, Procedia Engineering, vol. 38, (2012), pp. 2998-3004, ISSN 1877-7058, http://dx.doi.org/10.1016/j.proeng.2012.06.350.

[3] H. B. Mahmood, "Transport layer security protocol in Telnet", Communications, APCC The 9th Asia-Pacific Conference on Computer Networks, vol. 3, (2003),DOI: 10.1109/APCC.2003.1274255.

[4] V. L. Voydock and S. T Kent, "Security mechanisms in a transport layer protocol", Computer Networks (1976), vol. 8, Issues 5-6, (1984) October-December, pp. 433-449, ISSN 0376-5075, http://dx.doi.org/10.1016/0376-5075(84)90006-0.

[5] V. L. Voydock and S. T. Kent, "Security mechanisms in a transport layer protocol, Computers \& Security, vol. 4, Issue 4, (1985) December, pp. 325-341, pp. 0167-4048, ISSN, http://dx.doi.org/10.1016/01674048(85)90051-3.

[6] S. Sengupta, "An approach to provide a network layer security model with QR code generated with shuffled GPS parameters as embedded keys traveling over Internet using existing IPv4 mechanism", Computer Networks, vol. 57, Issue 11, (2013) August 5, pp. 2313-2330.

[7] J. Jürjens, "A domain-specific language for cryptographic protocols based on streams", The Journal of Logic and Algebraic Programming, vol. 78, Issue 2, (2009) January, pp. 54-73, ISSN 1567-8326, http://dx.doi.org/10.1016/j.jlap.2008.08.006.

[8] A. Espejel-Trujillo, I. Castillo-Camacho, M. Nakano-Miyatake and H. Perez-Meana, "Identity Document Authentication Based on VSS and QR Codes", Procedia Technology, vol. 3, (2012), pp. 241-250, ISSN 2212-0173, http://dx.doi.org/10.1016/j.protcy.2012.03.026.

[9] P. A. Shah, M. Yousaf, A. Qayyum and H. B. Hasbullah, "Performance comparison of end-to-end mobility management protocols for TCP", Journal of Network and Computer Applications, vol. 35, Issue 6, (2012) November, pp. 1657-1673, ISSN 1084-8045, http://dx.doi.org/10.1016/j.jnca.2012.05.002. 

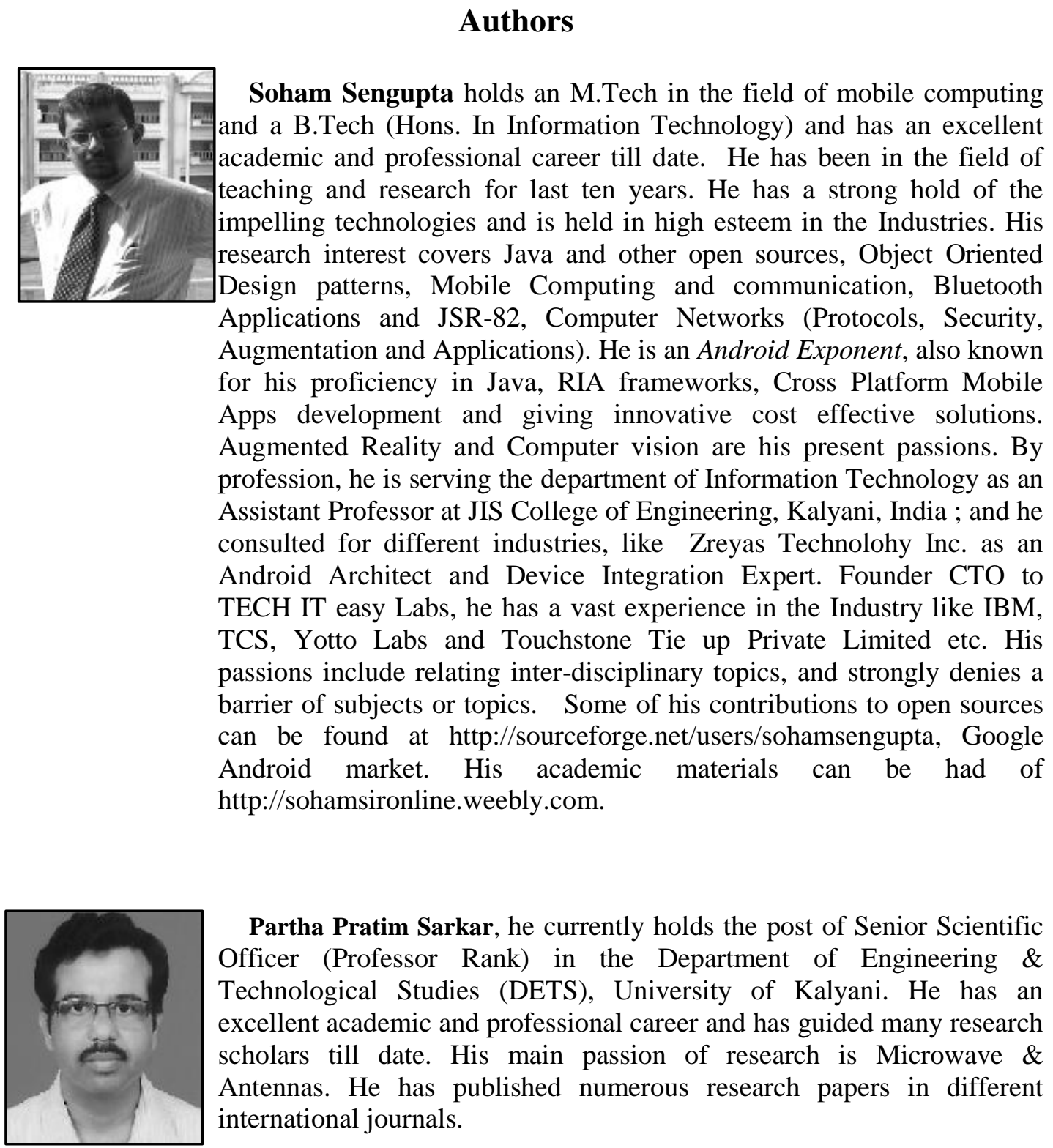

Partha Pratim Sarkar, he currently holds the post of Senior Scientific Officer (Professor Rank) in the Department of Engineering \& Technological Studies (DETS), University of Kalyani. He has an excellent academic and professional career and has guided many research scholars till date. His main passion of research is Microwave \& Antennas. He has published numerous research papers in different international journals. 
International Journal of Security and Its Applications Vol. 9, No. 3 (2015) 